\title{
Glider Observations of a Mesoscale Oceanic Island Wake
}

\author{
Kristin L. Zeiden, DANiel L. Rudnick, And Jennifer A. MACKinnon \\ Scripps Institution of Oceanography, University of California, San Diego, La Jolla, California
}

(Manuscript received 6 November 2018, in final form 31 May 2019)

\begin{abstract}
In this study, a 2-yr time series of velocity profiles to $1000 \mathrm{~m}$ from meridional glider surveys is used to characterize the wake in the lee of a large island in the western tropical North Pacific Ocean, Palau. Surveys were completed along sections to the east and west of the island to capture both upstream and downstream conditions. Objectively mapped in time and space, mean sections of velocity show the incident westward North Equatorial Current accelerating around the island of Palau, increasing from 0.1 to $0.2 \mathrm{~m} \mathrm{~s}^{-1}$ at the surface. Downstream of the island, elevated velocity variability and return flow in the lee are indicative of boundary layer separation. Isolating for periods of depth-average westward flow reveals a length scale in the wake that reflects local details of the topography. Eastward flow is shown to produce an asymmetric wake. Depth-average velocity time series indicate that energetic events (on time scales from weeks to months) are prevalent. These events are associated with mean vorticity values in the wake up to $0.3 f$ near the surface and with instantaneous values that can exceed $f$ (the local Coriolis frequency) during periods of sustained, anomalously strong westward flow. Thus, ageostrophic effects become important to first order.
\end{abstract}

\section{Introduction}

Island wakes may be a significant sink of momentum for ocean currents and a source of vorticity in the interior, thus transforming incident currents. Islands in the path of energetic flows are often observed to have leeward flow reversals that are associated with the separation of a topographic boundary current (Heywood et al. 1990). This recirculation may detach in the form of wake eddies, which can transport trapped water mass properties and vorticity up to hundreds of kilometers downstream (Barkley 1972; Caldeira et al. 2014). In the case of the Hawaiian Islands, the combination of wind stress generated by the island mountains and the flow of swift geostrophic currents generates an ocean-wind wake that can extend thousands of kilometers (Xie et al. 2001). These island wakes have also been shown to impact biological processes. The domed isopycnals of cyclonic eddies can increase nutrient supply to the euphotic zone and promote biological productivity in otherwise low-productivity regions of the ocean (e.g., Dickey et al. 2008; Andrade et al. 2014), and anticyclonic eddies have been shown to concentrate organic matter far downstream (Sangra et al. 2007; Aristegui and Montero 2005). While numerous laboratory and numerical studies

Corresponding author: Kristin L. Zeiden, kfitzmorris@ucsd.edu have addressed the physics governing wakes, oceanic observations of currents around islands are rarer. The observational challenge lies in the temporal and spatial variability of flow past islands. In this study, two years of sustained glider observations (Rudnick and Cole 2011) provide the mean current patterns and their variability around the island of Palau in the tropical North Pacific on horizontal scales of $10-100 \mathrm{~km}$, vertical scales of $10 \mathrm{~m}$, and temporal scales as short as a week.

For flows with rotation, a reasonable measure of eddy intensity is the Rossby number Ro, here defined as the ratio of relative to planetary vorticity $(\mathrm{Ro}=\zeta / f)$. Here Ro is a signed quantity, as used in, for example, Whitt and Thomas (2013) and Rudnick (2001). Because the lateral growth of these eddies is limited by the island cross section, they have a Ro that is the same order of magnitude as the "island" Rossby number, $\operatorname{Ro}_{I}=U /(L f)$, where $U$ is a characteristic velocity scale and $L$ is the island cross section (Teinturier et al. 2010; Dong et al. 2007). This relationship has also been observed in the real ocean (Caldeira et al. 2014; Aristegui et al. 1994; Andrade et al. 2014; Heywood et al. 1990; Chang et al. 2013). In modeling and laboratory studies, there is evidence that rotation tends to inhibit the shedding of eddies as well as produce an asymmetry between anticyclonic and cyclonic eddies, when compared to flows with no background 
rotation (Heywood et al. 1996; Dong et al. 2007; Teinturier et al. 2010). Furthermore, for islands with strong variation in the Coriolis parameter (i.e., $f=f_{0}+\beta y$ cannot be reasonably approximated as a constant $f_{0}$ ), eastward flows have been shown to generate stationary Rossby waves which are believed to inhibit boundary layer separation (Boyer and Davies 1982). Because these asymmetric effects of background rotation are difficult to observe directly in the real ocean, knowledge of the signed Ro is necessary for making comparisons to these idealized studies. This study quantifies Ro both upstream and downstream of Palau and compares average properties of the currents over instances of eastward and westward flow.

Island wakes are also known to be highly variable, as demonstrated by satellite and in situ observations. Synoptic surveys of island wakes often capture significantly different wakes when sampled at different times. Heywood et al. (1990) demonstrated this variability using two rapid ship surveys around the island of Aldabra. They initially observed moderate currents and weak leeward return flow, but later found stronger flows and an associated shed vortex. Bowman et al. (1996) obtained similar observations between two surveys completed 1 year apart near Barbados. Island wakes have been shown to have significant spatial variability as well. Aristegui et al. (1994) used XBT and CTD data to describe the spatial structure of individual eddies in the vicinity of Gran Canaria. These eddies had horizontal length scales similar to the island diameter, but with different vertical length scales. These and other synoptic surveys produce high-resolution "snapshots" of coherent structures. To better understand island wake variance, authors have increasingly incorporated satellite data into their analysis. Hsu et al. (2017) used a 6-month record of satellite sea surface height to calculate the statistics of island wake spatial scales in the Kuroshio, as well as quantify mean values of incident velocity during times with and without vortex shedding. They found that velocities were on average twice as strong during periods of vortex shedding. Andrade et al. (2014) used 10 years of satellite data to track eddies near the Juan Fernández Islands using chlorophyll-a data from satellites, and discovered a seasonality in vortex shedding rates related to changes in wind stress and current direction. Caldeira et al. (2014) combined satellite observations with in situ Lagrangian observations to follow the evolution of a single anticyclonic eddy in the lee of Madeira Island for 3 months, with a core Ro magnitude of up to 0.7 . While satellite observations enable longer time series, the decreased resolution and dependence on sea surface height anomalies to estimate surface currents limits observations to large, mesoscale eddies in quasigeostrophic balance. Here mesoscale is defined as length scales greater than the first baroclinic Rossby radius of deformation (Chelton et al. 1998), often estimated as $\mathrm{Rd}=N H / f$, where $N$ and $H$ are characteristic stratification and surface layer thickness, respectively. Submesoscale eddies with potentially high Rossby numbers are not likely to be well characterized by satellite observations. This limitation underscores the need for obtaining sustained observations of absolute velocities in the vicinity of islands. In one of the few studies to do so, Teague et al. (2002) used a 10-month record of ADCP velocities up- and downstream of Tsushima Island to quantify mean properties of the wake and its variability. They observed elevated variance downstream, which they attributed in part to eddy shedding in a later study (Teague et al. 2005). They concluded that this variability leads to poorly defined mean velocities downstream, thus demonstrating how synoptic measurements of island wakes may not be well representative of the mean. There is a clear need for more sustained in situ observations to improve our understanding of island wake variability, and how they relate to the mean properties of island wakes.

To help address this gap, we present observations from repeat glider sections to the east and west of the northern end of Palau, a large archipelago in the tropical North Pacific Ocean situated in the path of the westward North Equatorial Current. Directionally dependent mean sections of velocity and vorticity are used to demonstrate that there is a recirculation in the lee of the island during periods of strong westward flow. This recirculation is accompanied by flow acceleration and strong vorticity with correspondingly high Rossby numbers (up to $|\mathrm{Ro}|=0.3$ near the surface) for an island this size $[L \sim O(200) \mathrm{km}]$ with moderate incident current speeds $\left[U \sim O(0.1) \mathrm{m} \mathrm{s}^{-1}\right]$. We will show that these high Ro are related to a wake length scale that reflects local details in the topography and that energetic events can induce Ro exceeding $O(1)$. In contrast, the wake generated during eastward flow does not generate comparably large Ro. This study is part of a larger field campaign [an Office of Naval Research Departmental Research Initiative called "Flow Encountering Abrupt Topography" (FLEAT)] that broadly aims to describe the Palau island wake at a variety of scales and to increase our understanding of how island wakes are generated and how they impact regional circulation.

This paper is organized as follows: section 2 details the data and methods utilized in this study, section 3 presents results characterizing the mean flow around Palau and its variability, section 4 presents a discussion, and section 5 is a summary of our conclusions. 


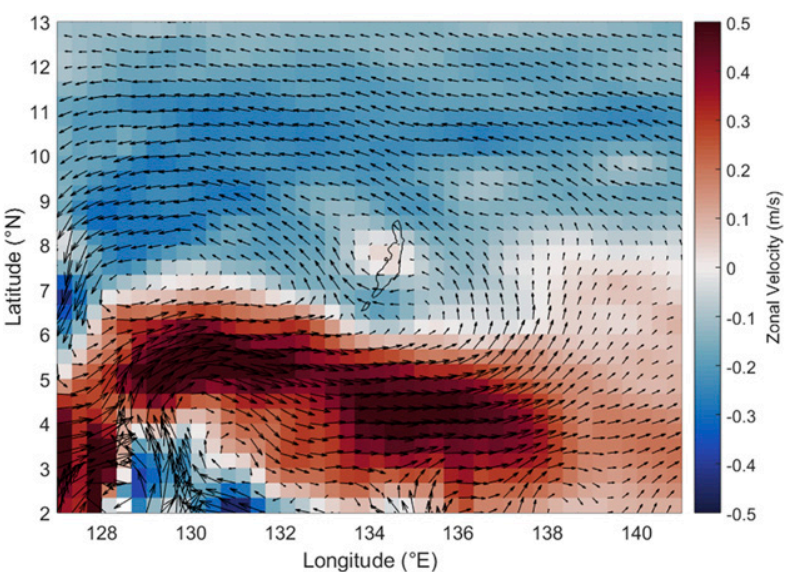

FIG. 1. OSCAR surface currents (vectors) averaged over the glider observation period and shaded by zonal velocity. The weak, broad westward current to the north of Palau (black contour) is the NEC, and the strong eastward current to the south is the NECC. The ME lies to the west. The variability of these three major regional circulation features has a major impact on the local circulation around Palau (Heron et al. 2006).

\section{Data and methods}

\section{a. Oceanographic setting}

Palau is an archipelago oriented normal to two major zonal geostrophic currents in the western tropical Pacific - the North Equatorial Current (NEC) and North Equatorial Counter Current (NECC). The regional circulation around Palau has been studied in detail (Schonau and Rudnick 2015; Qiu and Lukas 1996; Qiu et al. 2013a,b; Heron et al. 2006; Kashino et al. 2009), and the major surface features are identifiable in OSCAR surface currents (described below in section $2 \mathrm{~d}$ ) averaged over the observational period (Fig. 1). They are the NEC to the north of Palau, the NECC to the south, and the Mindanao Eddy (ME) to the west. Glider surveys conducted by Schonau and Rudnick (2015) from 2009 to 2014 show the NEC is made up of a series of surface intensified cores between $8^{\circ}$ and $20^{\circ} \mathrm{N}$ that migrate north to south with a seasonal cycle. The core velocities can reach up to $0.5 \mathrm{~m} \mathrm{~s}^{-1}$. Underlying the NEC are a series of eastward subthermocline jets, the North Equatorial Undercurrents (NEUCs), which Qiu et al. (2013b) suggest are generated by Rossby wave instability.

The main island of Palau is centered around $7.5^{\circ} \mathrm{N}$, $134.5^{\circ} \mathrm{E}$ (Fig. 2). Although most of the archipelago is subsurface, the $50-\mathrm{m}$ isobath extends almost $200 \mathrm{~km}$ between $6.9^{\circ}$ and $8.5^{\circ} \mathrm{N}$ (Smith and Sandwell 1997). Beyond this isobath, gradients in the bathymetry can reach slopes of up to $45^{\circ}$. Our survey was designed to capture the upstream and downstream conditions of the NEC as it circumvents Palau to the north. The glider

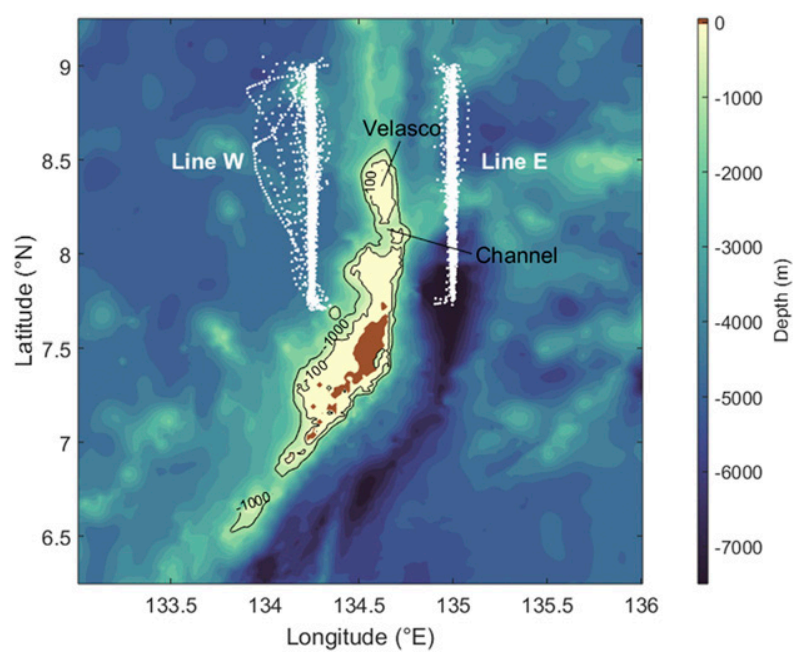

FIG. 2. Glider dives are plotted in white over the local bathymetry. Gliders sampled between $7.75^{\circ}$ and $9^{\circ} \mathrm{N}$, along $134.25^{\circ}$ (Line $\mathrm{W}$ ) and $135^{\circ} \mathrm{E}$ (Line E). Over 5500 dives were completed between October 2015 and January 2018. The 100- and 1000-m isobaths are contoured in black to emphasize the steepness of the topography around Palau. Centered between the glider lines is a sunken reef called Velasco which is $20 \mathrm{~m}$ deep around the rim. Between Velasco and Palau is a narrow, deep channel with a sill reaching just under $1000 \mathrm{~m}$.

lines are located on either side of Velasco, an atoll primarily composed of a sunken reef. Although the reef is entirely subsurface it can be as shallow as $20 \mathrm{~m}$ around the rim. To the south of Velasco is a deep channel reaching just under $1000 \mathrm{~m}$ at the sill. The glider lines were centered around the anticipated topographic separation point at the northernmost extent of the reef.

\section{b. Dataset description}

Spray gliders are autonomous underwater vehicles that change buoyancy to profile from the surface down to as far as $1000 \mathrm{~m}$ (Sherman et al. 2001). The gliders carry a SeaBird Conductivity Temperature Depth sensor (CTD), a Seapoint Fluorometer, and a $1-\mathrm{MHz}$ Nortek Acoustic Doppler Current Profiler (AD2CP). The glider moves through the water at an average rate of $0.25 \mathrm{~m} \mathrm{~s}^{-1}$ in the horizontal plane and $0.1 \mathrm{~m} \mathrm{~s}^{-1}$ in the vertical direction, and data are collected during ascent. The processing of $\mathrm{AD} 2 \mathrm{CP}$ data follows Todd et al. (2017) combining the relative velocity from the AD2CP with the depth-average velocity measured by the glider (Rudnick et al. 2018). Data are transmitted via satellite each time a glider surfaces, while raw data are stored on a flash drive and collected upon recovery.

The glider data in this study were collected between 28 October 2015 and 13 January 2018, along two parallel meridional sections $82 \mathrm{~km}$ apart on either side of Velasco reef. The sections each run between $7.75^{\circ}$ and 
$9.00^{\circ} \mathrm{N}$, one at $134.25^{\circ}$ and $135.00^{\circ} \mathrm{E}$ (hereinafter "Line W" and "Line E," respectively; Fig. 2). A total of 106 sections were completed on Line $\mathrm{W}$, and 85 were done on Line E. Each section took an average of 7 days to complete, and each mission completed an average of 14 sections. The gliders collectively achieved an average profile-to-profile horizontal resolution of $4.7 \mathrm{~km}$ and temporal resolution of $6 \mathrm{~h}$. The profiles are down to $1000 \mathrm{~m}$ and are vertically averaged into $10-\mathrm{m}$ bins after quality controlling the CTD data and computing velocity with the AD2CP data.

A few gaps in the time series were caused by operational issues. The second glider mission along Line $\mathrm{W}$ returned with a corrupted flash drive. Binned CTD data from the satellite communications are available, but there are no $\mathrm{AD} 2 \mathrm{CP}$ data from this run, spanning 16 February through 6 June 2016. Coincidentally, during the same period the other glider (running Line E) was swept north in an anomalously strong northward current. As a result there are no $\mathrm{AD} 2 \mathrm{CP}$ data on either line during this period. Shorter gaps in the $\mathrm{AD} 2 \mathrm{CP}$ data are due to deployment and recovery.

\section{c. Objective map}

Figure 3 shows an example zonal velocity section along Line E. Internal wave motions and tides appear in the section as isopycnal heaving and velocity variability on spatial scales shorter than $30 \mathrm{~km}$ (Rudnick and Cole 2011). To filter out high-frequency variability, AD2CP data were objectively mapped onto a regular grid $(3 \mathrm{~km}$ by 3.5 days) using a Gaussian autocovariance. Statistics are assumed to be stationary and homogeneous. To determine the appropriate time and length scales for the Gaussian function, the autocorrelation of each variable was calculated as a function of lag in space and time. Anomalies were calculated at each depth with respect to a linear trend in latitude and averaged into bins of 14 days and $5.6 \mathrm{~km}$. These bins correspond to 2 times the average separation between sections in time, and the average horizontal resolution along the section. The autocorrelation of zonal velocity along Line $\mathrm{E}$ and Line W is shown in Fig. 4. Zonal velocity is shown as we are interested primarily in flow past the island. Additionally, zonal velocity exhibits the shortest time and length scales of all variables and so places a lower limit on them. Distance north is taken to be positive, and so the slope in autocorrelation along Line E corresponds to anomalies propagating northward at a velocity of $0.05 \mathrm{~m} \mathrm{~s}^{-1}$. This is the average meridional velocity down to $200 \mathrm{~m}$ along Line $\mathrm{E}$ (the average base of the pycnocline, not shown), where there is also significant mesoscale eddy activity (Schonau and Rudnick 2015). This suggests that the slope in autocorrelation is due to the meridional advection of

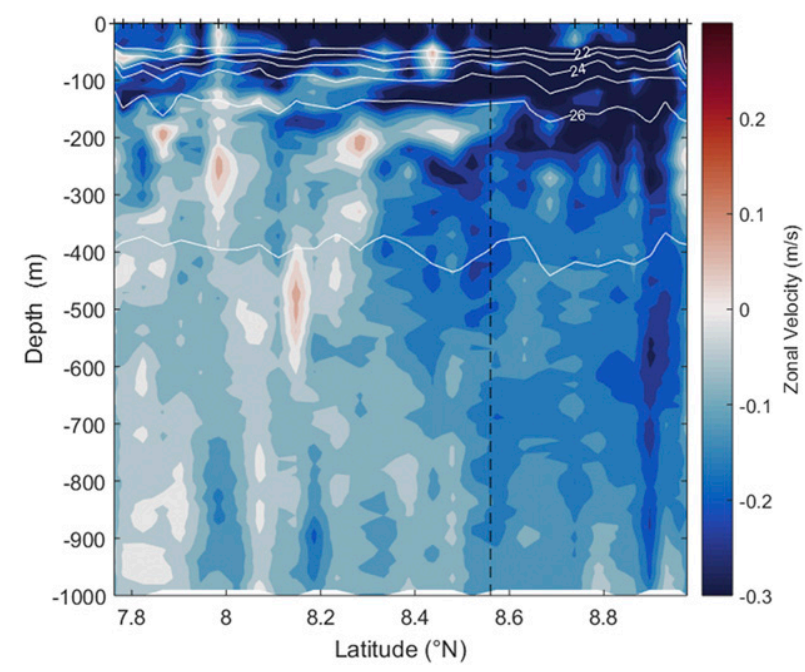

FIG. 3. Example glider section along Line E, completed between 24 Nov and 2 Dec 2015. Filled contours display zonal velocity, with blue indicating westward velocity. Isopycnals (white contours) exhibit heaving in part due to aliased internal wave motions. The density interval is $1 \mathrm{~kg} \mathrm{~m}^{-3}$. Line $\mathrm{E}$ is upstream in the mean, capturing the surface-intensified westward NEC as shown here.

mesoscale eddies in the NEC. The decorrelation length scale along Line $\mathrm{W}$ is less than $50 \mathrm{~km}$, in sharp contrast to Line $\mathrm{E}$ which demonstrates almost total meridional coherence. The significance of this disparity is discussed in section 3 . The decorrelation time scale for both lines is no more than 2 weeks. We choose $30 \mathrm{~km}$ and 14 days for decorrelation length and time scales to preserve the variability on the shortest reasonable scales attainable by the glider data. We do not resolve all scales that may be energetic, and it is possible that there are higher Rossby number motions than those observed in this study occurring on scales less than $30 \mathrm{~km}$ and 14 days.

Variables were mapped individually on levels separated by $10 \mathrm{~m}$ in the vertical direction. The ratio of noise to signal variance was taken to be 0.1 , and points in the map with error-to-signal variance greater than 0.1 are masked. The result is a regular grid in latitude, depth, and time for each variable, with respective resolutions of $3 \mathrm{~km}, 10 \mathrm{~m}$, and 3.5 days and overall spans of $140 \mathrm{~km}$, $1000 \mathrm{~m}$, and 807 days. The total number of objectively mapped AD2CP sections along Line $\mathrm{W}$ and Line $\mathrm{E}$ are 191 and 154, respectively. All mapped sections on Line E correspond to a mapped section along Line W; however, there are sections for which there are only mapped data along Line $\mathrm{W}$, meaning there are 154 total sections with data mapped along both lines. Each section corresponds to a single date and time, compared to the glider surveys which span about a week. Figure 5 shows a 

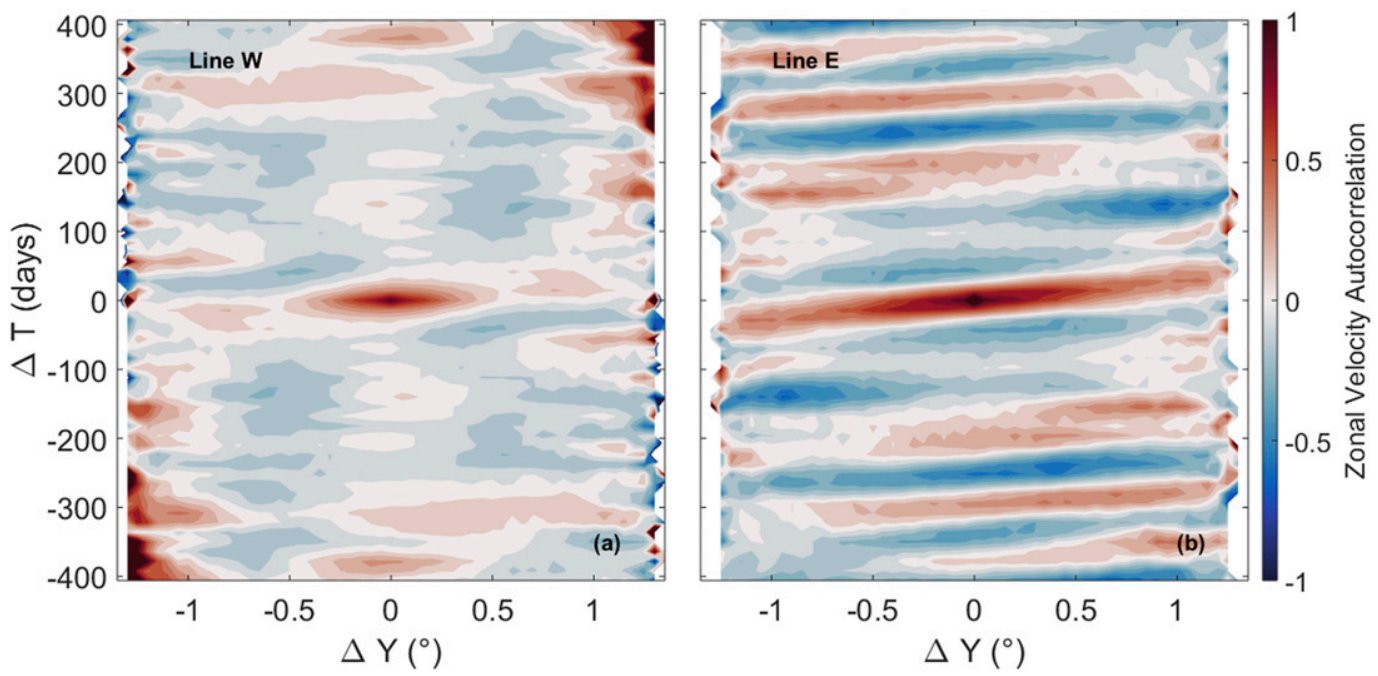

FIG. 4. Autocorrelation of zonal velocity as a function of lag in latitude and time, calculated at each 10-m depth bin and averaged over the water column for (a) Line W and (b) Line E. Both lines exhibit a decorrelation time scale of no more than 2 weeks, and while zonal velocity is coherent across the line on Line E, the decorrelation length scale along Line $\mathrm{W}$ is less than $50 \mathrm{~km}$. These limiting time and length scales inform the choices made in creating an objective map.

section of the objective map that is concurrent with the survey period of the original example section in Fig. 3. The large-scale structure has been preserved while the smaller-scale fluctuations have been filtered. All subsequent calculations use the objectively mapped data.

\section{d. Eastward and westward flow definitions}

The zonal component of the currents moving past Palau dictate whether the vorticity produced is cyclonic or anticyclonic, with the potential to generate asymmetric wakes (e.g., Heywood et al. 1996). Further, strong variability of the flow direction can make interpreting an absolute mean difficult (e.g., Teague et al. 2005). To quantify this asymmetry and mitigate the impact of flow variability on interpreting the mean we calculated direction-dependent mean velocity sections. Time series of depth-average velocity vectors along each section demonstrate that velocity is largely coherent across Line E but exhibits latitudinal variance along Line $\mathrm{W}$, consistent with autocorrelations of zonal velocity (Fig. 6). Qualitative inspection reveals that the westward incident flow tends to split upstream at about $8.2^{\circ} \mathrm{N}$, with flow typically heading northward around the island when it is incident north of this latitude. Therefore, we use velocities north of $8.2^{\circ} \mathrm{N}$ to characterize the flow direction. We calculate the depth-and-latitude averaged velocity along each section and designate the flow as westward (eastward) if the direction is $\pm 60^{\circ}$ from west (east) along Line $\mathrm{E}$ (Line W). Because each line is treated independently, a small portion of sections fell into both categories. Visual inspection of these sections suggested that they were most like the westward sections and are included in that mean. However, this inclusion did not change the results markedly. There were 90 (42) sections with westward (eastward) flow. This number corresponds to $58 \%$ (27\%) of sections that have mapped data along both Line E and Line W. We therefore expect averages taken over all westward sections to resemble

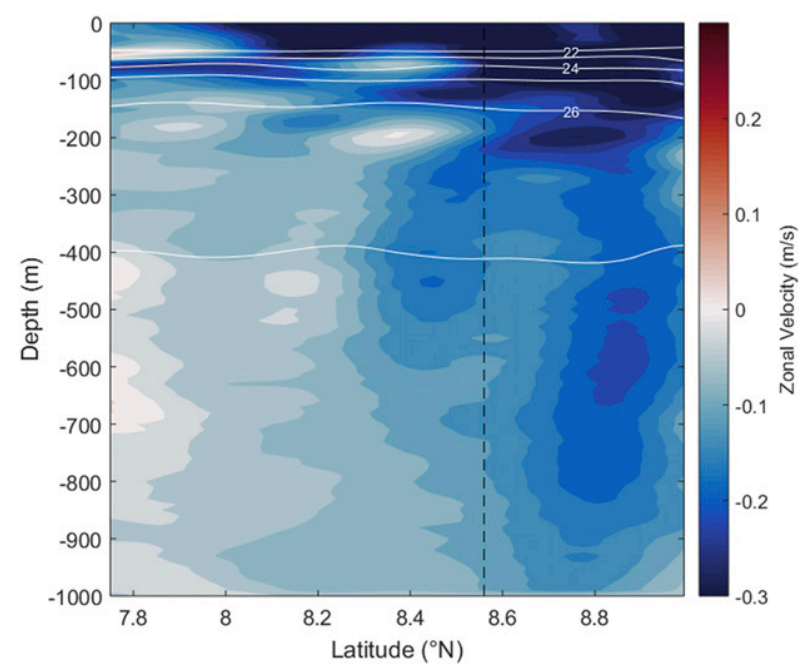

FIG. 5. Example objectively mapped glider section along Line E, corresponding to $29 \mathrm{Nov} 2015$. The plotting scheme is the same as in Fig. 3, and the section is roughly concurrent to demonstrate the smoothing achieved by the objective map. Map length and time scales of $30 \mathrm{~km}$ and 14 days, respectively, were informed by the autocorrelation of zonal velocity (Fig. 4). 

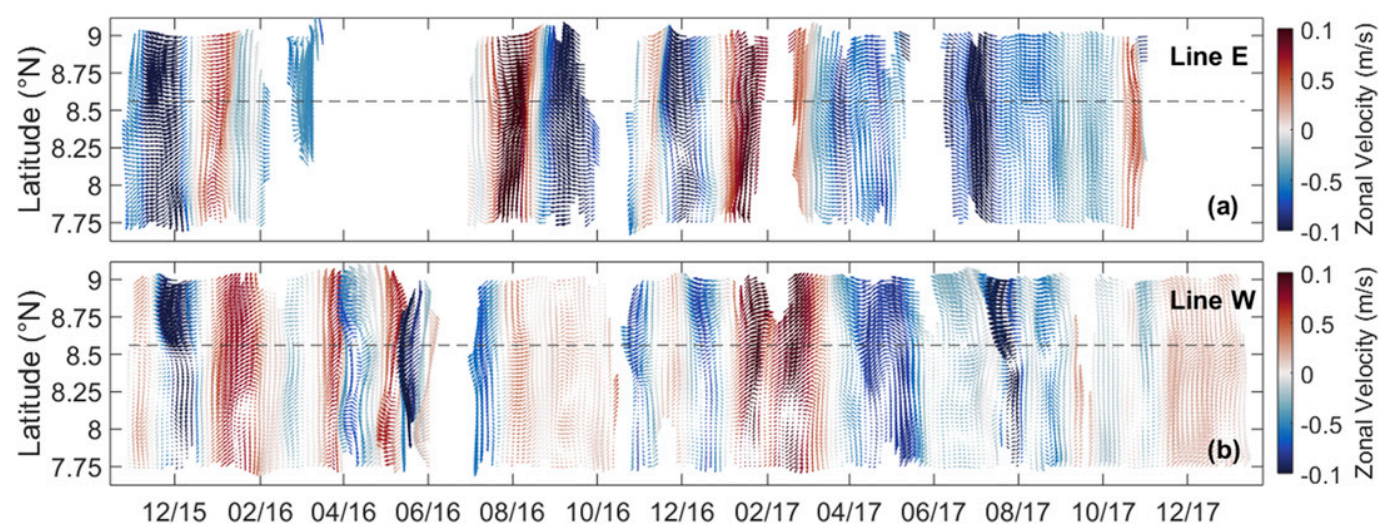

FIG. 6. Time series of depth-averaged velocity vectors for each section, shaded by the depth-latitude average zonal velocity across each section. The northernmost extent of Velasco reef is marked with a horizontal dashed gray line. Velocity is mostly coherent along (a) Line E and exhibits greater latitudinal variance along (b) Line W, especially south of the reef.

the total mean. No sections for which there were data only along Line $\mathrm{E}$ or Line $\mathrm{W}$ are included.

\section{e. OSCAR surface currents}

Ocean Surface Current Analysis (OSCAR) Third Degree near-surface currents are used in this study to provide regional context for the glider data close to Palau. The OSCAR data were obtained from the Jet Propulsion Laboratory (JPL) Physical Oceanography Distributed Active Archive Center (PO.DAAC) and were developed by Earth and Space Research (ESR 2009). Horizontal velocities are computed using sea surface height (SSH), surface wind and sea surface temperature (SST) by combining geostrophic, Ekman, and Stommel dynamics (Bonjean and Lagerloef 2002). Each component (i.e., SSH, SST, and wind vector) is derived from a combination of satellite and in situ instruments, and the final product is mapped onto a 5 -day by $1 / 3^{\circ}$ (both in latitude and longitude) grid. The OSCAR product does not represent local acceleration and nonlinearities. As such it is best used to describe the large-scale circulation, as in this study. As a result of this, surface currents are mapped across Palau, as evident in Fig. 1. Further information about the processing methods for OSCAR surface currents can be found in Bonjean and Lagerloef (2002).

\section{Results}

\section{a. Mean currents and variability}

Mean sections of velocity show that on average, the incident westward NEC accelerates around the northern end of Palau and experiences flow separation that induces a reversal of the currents in the lee (Fig. 7).
Because zonal velocity is primarily westward, Line $\mathrm{E}$ is upstream in the mean and Line $\mathrm{W}$ is downstream.

Upstream, incident currents are northwestward and both components of velocity are surface intensified (Figs. 7b,d). Despite this vertical shear, the flow direction is relatively uniform with depth. Depth-average velocity is strongest near the northernmost extent of the reef (gray dashed lines) and diminishes south of $8.2^{\circ} \mathrm{N}$. At the northern end of the section there is subthermocline eastward flow, between about 300- and 600-m depth. This may be an eastward-flowing NEUC that typically lies to the north but occasionally migrates south into the region sampled by the glider (Schonau and Rudnick 2015).

Downstream the flow develops latitudinal structure (Figs. 7a,c). North of the reef, zonal velocity is westward and sheared, similar to the current upstream. However, the magnitude of the current increases substantially, from about 0.1 to $0.2 \mathrm{~m} \mathrm{~s}^{-1}$ near the surface. This strongly suggests that the flow accelerates as it passes the island. Zonal velocity decays to zero close to the edge of the reef and changes sign in the lee, indicative of flow separation. Currents are eastward almost everywhere in the lee of the island. There is some westward flow shallower than $200 \mathrm{~m}$, between $8^{\circ}$ and $8.2^{\circ} \mathrm{N}$. Below this westward flow, the eastward flow is weakest. Meridional velocity is northward, surface intensified, and weakest where the zonal flow goes to zero. Depth-averaged velocity vectors illustrate the resulting meander of the wake (Fig. 7e).

Velocity variability similarly has features induced by the island (Fig. 8). Variability, measured as the standard deviation of velocity between sections (both zonal and meridional), is surface intensified and elevated to the north of the reef along both lines. Absolute differences between Line E and Line W (not shown) 

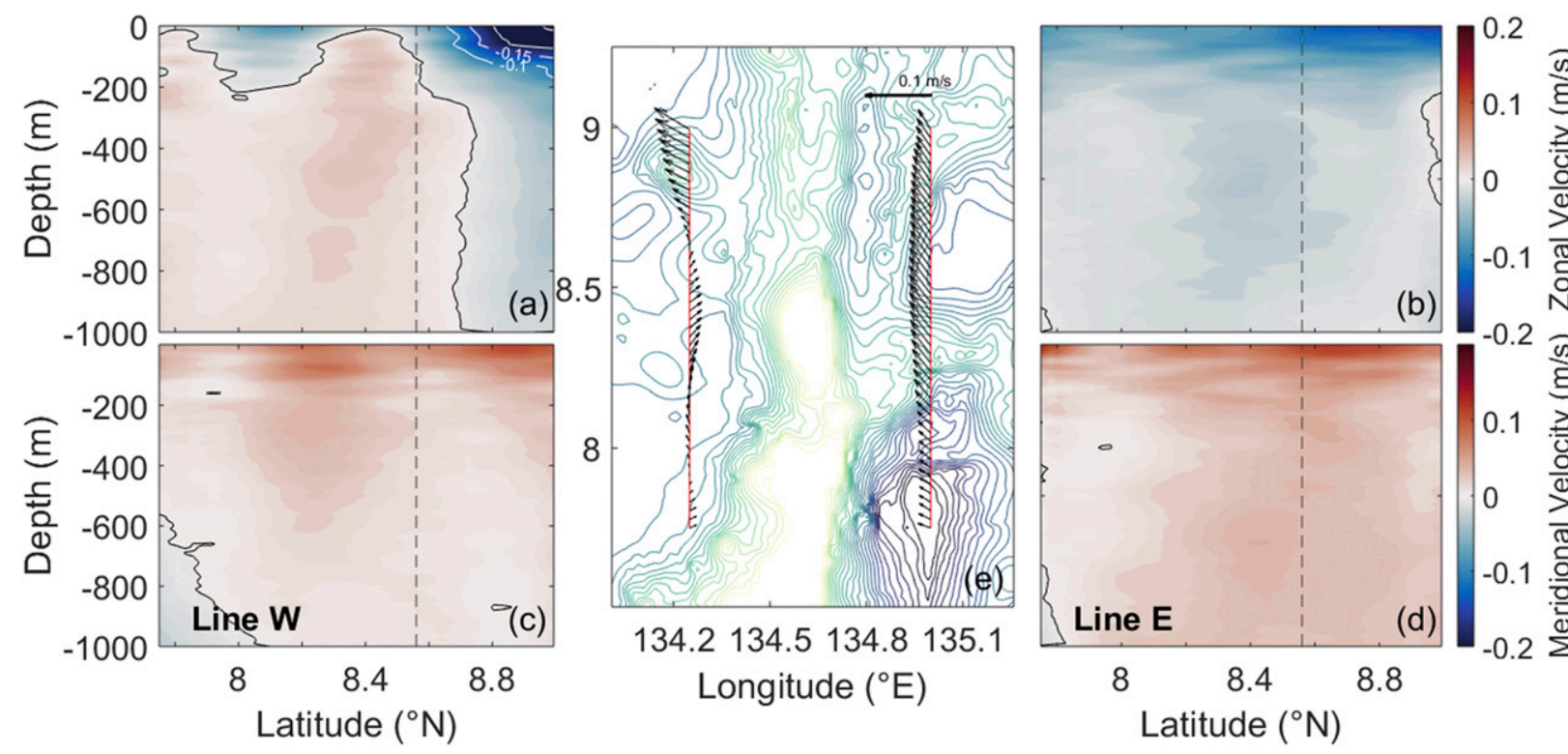

FIG. 7. Mean sections of (a),(b) zonal and (c),(d) meridional velocity along (right) Line E and (left) Line W, as well as (e) mean depthaverage velocity vectors plotted against bathymetry. The northernmost extent of Velasco reef is indicated with vertical dashed gray lines in (a)-(d). Negative (positive) indicates eastward and southward (westward and northward) currents. Black contour lines are zero velocity. Velocities stronger than -0.1 are contoured in white, with a $0.05 \mathrm{~m} \mathrm{~s}^{-1}$ contour interval. The flow is surface intensified and incident along Line $\mathrm{E}$ (westward; NEC). Therefore, Line $\mathrm{E}$ is upstream in the mean and Line $\mathrm{W}$ is downstream. The incident flow is strongest close to the reef extent and weakest to the south, indicative of topographic blocking. Downstream along Line W, there is acceleration north of the ridge and return flow in the lee of Velasco reef.

indicate that zonal velocity variability increases downstream and north of the reef by about $30 \%$ near the surface, and decreases by up to $50 \%$ in the lee (in the subthermocline). Meridional velocity variability has minimal lateral structure (Figs. 8c,d). Teague et al. (2002) found similar elevated variance downstream of Tsushima island, which, as mentioned earlier, they attributed in part to eddy shedding in a later study (Teague et al. 2005).

\section{b. Westward flow}

Selecting for westward flow produces sections of mean velocity that closely resemble the total mean, but with a few differences that have significant dynamic implications (Fig. 9). As with the total mean, upstream zonal velocity is primarily northwestward and highly surface intensified. However the maximum surface zonal velocity exceeds $0.2 \mathrm{~m} \mathrm{~s}^{-1}$ near the northern end of Line E, and the subthermocline flow diverges near $8.2^{\circ} \mathrm{N}$. The latter is strong evidence of topographic blocking, that is, upstream influence of the island. This feature did not appear in velocity sections averaged over the entire time series (Fig. 7).

Downstream, changes to the mean are more striking. North of the reef the mean surface zonal velocity accelerates to over $0.3 \mathrm{~m} \mathrm{~s}^{-1}$, and in the lee of the island the return flow is confined to a $40 \mathrm{~km}$ region from $8.2^{\circ} \mathrm{N}$ to the reef edge (Fig. 9a). Plotting the bathymetric cross section of Velasco over zonal velocity (dashed black line) suggests a forcing for this length scale. The sill of the channel separating Velasco reef from the rest of Palau is deep enough to allow westward flow through to the lee. This channel flow was observed to reach values exceeding $0.5 \mathrm{~m} \mathrm{~s}^{-1}$ as part of another FLEAT study using SeaSoar towed profilers (C. Ou and T. M. S. Johnston 2018, personal communication). This strong current appears to limit the return flow to the area directly behind the reef.

The wake during westward flow has a more complex depth structure than the total mean wake. Depthaverage velocity vectors for westward flow are plotted in intervals of $100 \mathrm{~m}$ in Fig. 10. These vectors highlight the strength of the vertical shear in the incident current, which may alter the flow dynamics significantly with depth. Downstream (Fig. 10b), acceleration is apparent north of the ridge. Westward flow through the channel is so strong in the upper $200 \mathrm{~m}$ that it almost completely overpowers the shallow eastward return flow. As the channel flow weakens with depth the magnitude of the return flow increases, suggesting that changes in the topography have a first-order impact on the strength of the wake. Near the surface, the meridional component of velocity is northward, but as the flow weakens with depth it turns southward. As a 


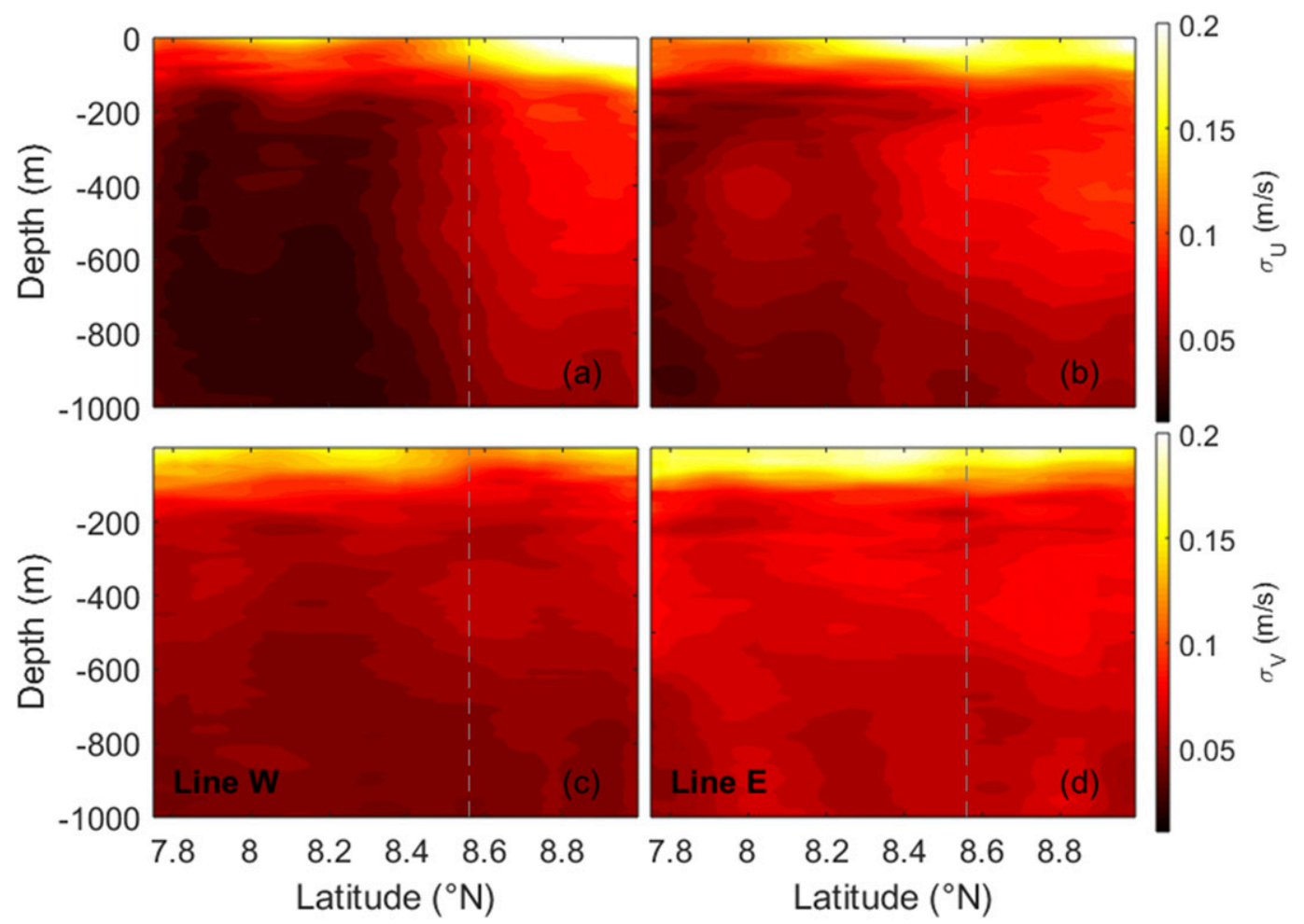

FIG. 8. (a),(b) Zonal and (c),(d) meridional velocity variability (standard deviation) along (left) Line W and (right) Line E. Line E is upstream in the mean, and Line W is downstream. The northernmost extent of Velasco reef is indicated with vertical dashed gray lines in (a)-(d). Variability is elevated on the surface, as well as north of Velasco reef in zonal velocity along both lines. Variability decreases in the lee.

result the mean lateral position of the return flow moves south with depth.

The primary features of velocity variability that appear in the mean (i.e., surface intensification, patterns of downstream increased/decreased variability north/south of the reef) are apparent during westward flow as well, although overall the standard deviation is lower due to selection of similar flow configurations (Fig. 11). However in the total mean, variability across each line is elevated north of the reef. This feature no longer appears upstream (along Line E) after selecting for westward flow, leading to a relative increase in the standard deviation north of the ridge of over $100 \%$ as the flow accelerates. This suggests that elevated variability north of the ridge is a downstream phenomenon, tied to the flow acceleration and separation. Thus, we expect this pattern to be reversed for eastward flow.

\section{c. Eastward flow}

Mean sections of velocity during eastward flow reveal a striking asymmetry in both the wake and incident current (Fig. 12). For eastward flow, Line W is upstream and Line $\mathrm{E}$ is downstream. Although the depth-averaged flow is eastward across the reef (by definition), westward flow persists near the surface. In the upper $50 \mathrm{~m}$ zonal velocity is westward along Line $\mathrm{E}$ as well as the northern and southern ends of Line W, similar to the incident flow and wake generated during westward flow. The location of the return flow is more northward, likely due to the stronger incident meridional velocities along Line $\mathrm{E}$. This persistence of westward flow at the surface suggests that eastward flow may be a waning of the sheared westward flow rather than a total flow reversal, in which eastward flow would be similarly surface intensified in the eastward direction and coherent along Line W.

Nonetheless, the subthermocline upstream zonal velocity is entirely eastward. Meridional velocity diverges near $8^{\circ} \mathrm{N}$, suggestive of topographic blocking. Downstream, there is westward flow in the lee of the island south of $\sim 8.3^{\circ} \mathrm{N}$. However, meridional velocity in the lee is northward and greater in magnitude than zonal velocity, suggesting that the flow along Line E may instead be coming from the south, rather than from the west and across the reef. If this is so, it is unlikely that the westward flow along Line $\mathrm{E}$ (south of $8.2^{\circ} \mathrm{N}$ ) is return flow resulting from boundary layer separation. Velocity variability (not shown) is lower overall during eastward 


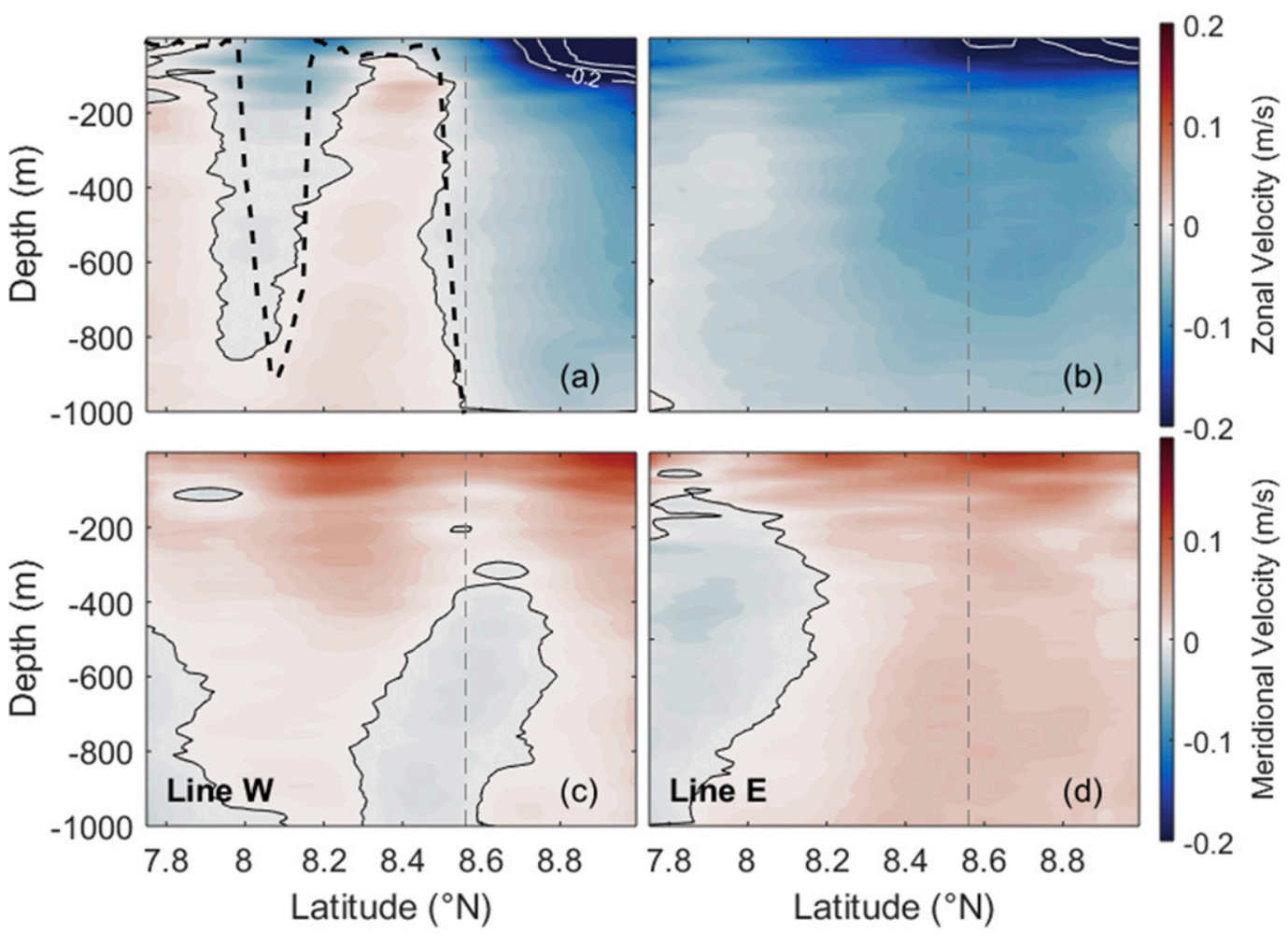

FIG. 9. Mean sections of (a),(b) zonal and (c),(d) meridional velocity along (right) Line E and (left) Line W after selecting for westward flow. The color scheme and contour lines are as in Fig. 7. Line E is upstream during westward flow, and Line $\mathrm{W}$ is downstream. The dashed black line in (a) shows the bathymetry along $134.5^{\circ} \mathrm{E}$, down the center of Velasco reef. Selecting for westward flow emphasizes topographic blocking upstream in (d) and reveals a length scale in the wake that reflects the size of Velasco reef rather than the entire island of Palau, likely due to flow through the narrow channel at $8^{\circ} \mathrm{N}$.

flow, but is elevated to the north of the reef and downstream. Depth-average velocity vectors (over 100-m intervals) highlight the persistence of westward flow at the surface, as well as the strength of the northward component of the flow downstream (Fig. 13). Although the incident subthermocline velocity is very similar to that of westward flow (reversed zonally), the wake structure is quite different for reasons suggested above. To better understand these asymmetries, OSCAR surface currents averaged over each flow regime are examined in section 4. If eastward flow cannot be considered a simple flow reversal, it is difficult to draw meaningful comparisons with any asymmetries predicted by quasigeostrophic theory (Boyer and Davies 1982; Musgrave et al. 2018).

\section{d. Vorticity}

The source of vorticity in the wake is thought to be the velocity gradient over the width of the frictional boundary layer (Kundu and Cohen 1990). Any attempt to characterize the wake behind Palau must therefore involve an estimate of the vorticity generated. Because the sections are meridional, we approximate vorticity using the meridional gradient in zonal velocity alone $(\zeta=-d U / d y)$. To estimate our error, we consider two plausible extremes. In the case of solid-body rotation (i.e., $-d U / d y=d V / d x$ ), this may be an underestimate of the magnitude of the vorticity by up to a factor of 2 . On the other hand, if the flow is entirely zonal then we have measured the total vorticity. Because there are strong jets through the channel and around the reef, it is implausible that zonal gradients are larger than meridional gradients. This suggests our approximation is valid, and at most an underestimate of the total vorticity. Further discussion of this approximation may be found in Rudnick (2001) and Shcherbina et al. (2013).

Mean vorticity during westward and eastward flow emphasizes the directional asymmetries previously identified in mean sections of velocity (Fig. 14). Here vorticity has been normalized by the local Coriolis parameter, giving the Rossby number $(\mathrm{Ro}=\zeta / f$, with $f=$ $\left.2.17 \times 10^{-5} \mathrm{~s}^{-1}\right)$. Downstream during depth-average westward flow (Fig. 14a), mean Ro exceed 0.3 near the surface. During depth-average eastward flow this 


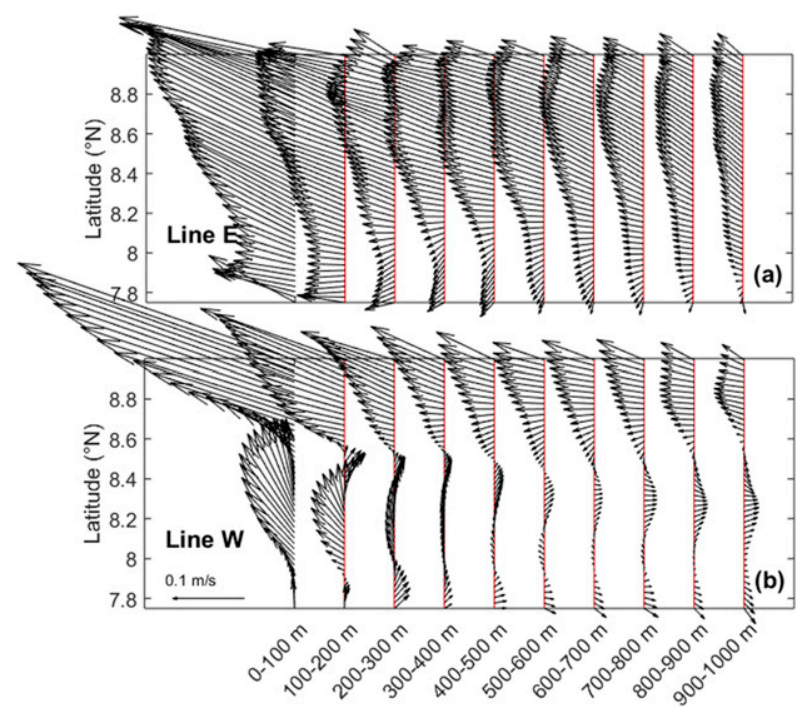

FIG. 10. Time-mean depth-average velocity vectors in intervals of $100 \mathrm{~m}$ along (a) Line E and (b) Line W, after selecting for westward flow. Line $\mathrm{E}$ is upstream during westward flow, and Line $\mathrm{W}$ is downstream. The wake exhibits a depth structure influenced by the topography as well as by the incident vertical shear.

feature appears upstream (Fig. 14c) and downstream Ro are weak (Fig. 14d), due to the persistence of westward flow at the surface. Ro variability along both lines (not shown) is high: $\sim 0.1$ in the subthermocline and up to 0.3 in the surface layer. Therefore the lack of a strong vorticity signature upstream during westward flow (Fig. 14b) implies that there is no preferred sense (cyclonic or anticyclonic) to the incident vorticity field, and the lateral structure downstream in the mean is due to the presence of the island.

\section{e. Event-driven variability}

Hovmöller diagrams of depth-average shallow (0-100 m) zonal velocity and normalized vorticity demonstrate that the return flow and large Ro downstream are consistent features throughout the time series, and that the high Ro variability is in large part due to energetic low-frequency events (Figs. 15, 16). This depth interval was selected to isolate the surface currents characterized by elevated variability. It is roughly equivalent to an isopycnal of $26 \mathrm{~kg} \mathrm{~m}^{-3}$ in the mean, which Schonau and Rudnick (2015) used to distinguish between the NEC and NEUCs.

Along Line E (upstream in the mean), zonal velocity is mostly westward and coherent across the section (Fig. 15a). Along Line W (downstream in the mean), return flow appears as a band of intermittent eastward velocity centered around $8.4^{\circ} \mathrm{N}$. This intermittency supports an interpretation of the wake as eddying but may also be explained by fluctuations in the strength of the incident current on time scales of days to weeks.
Although this higher-frequency variability persists across the entire time series, there are a few low-frequency events that dominate the signal. Particularly energetic periods include strong eastward flow in July of 2016 and January of 2017, and strong westward flow in July of 2017. The latter occurred during the longest period of westward flow captured in the time series. Although gaps in the sampling along Line E partially obscure the upstream velocity, the persistent pattern of westward currents and recirculation along Line W starting in March 2017 and through the end of the time series suggests that this event lasted at least 7 months. The strength of the shallow current fluctuates between 0.1 and $0.3 \mathrm{~m} \mathrm{~s}^{-1}$ for most of this period but exceeds $0.5 \mathrm{~m} \mathrm{~s}^{-1}$ during the summer of 2017.

These events have significant implications for the wake Ro over time, as demonstrated by similar Hovmöller diagrams of vorticity (Fig. 16). Along Line E there is no preferred sense to the vorticity, leading to low Ro in the mean $(|\mathrm{Ro}|<0.1$; Fig. 14). Along Line W however, the intrinsic background vorticity fluctuations are transformed into persistent features of elevated positive and negative vorticity. This is especially true during periods of sustained westward flow. Strong currents during July 2017 correspond to downstream vorticity values exceeding the local Coriolis frequency $f$ (i.e., Ro $>1$ ). By comparison, periods with strong eastward currents do not produce similarly strong negative vorticity downstream. This disparity is emphasized in a time series of section-integrated, depthaverage vorticity flux (Fig. 17a). There is a moderate peak in the vorticity flux along Line $\mathrm{W}$ in December of 2015 and substantial one in July 2017, both corresponding to periods of strong westward flow (Fig. 17b). Three shorter periods of eastward flow with similar intensities (January 2016, July 2016, January 2017) have no vorticity flux signature. These low-frequency, high Ro events are confined to the surface. Subthermocline $|\mathrm{Ro}|$ only briefly exceeds 0.2 , and it predominantly stays near 0.1 (not shown). The Ro of the surface wake is therefore up to an order of magnitude greater than the subthermocline.

\section{Discussion}

In this paper, glider observations are used to characterize the mean mesoscale flow around the northern end of Palau. On average, surface intensified westward flow encounters the meridionally elongated island normally, is topographically blocked and accelerates to pass the island. As the current flows around the reef it separates, leading to a region of return flow in the lee of the island. Velocity variability is elevated downstream 


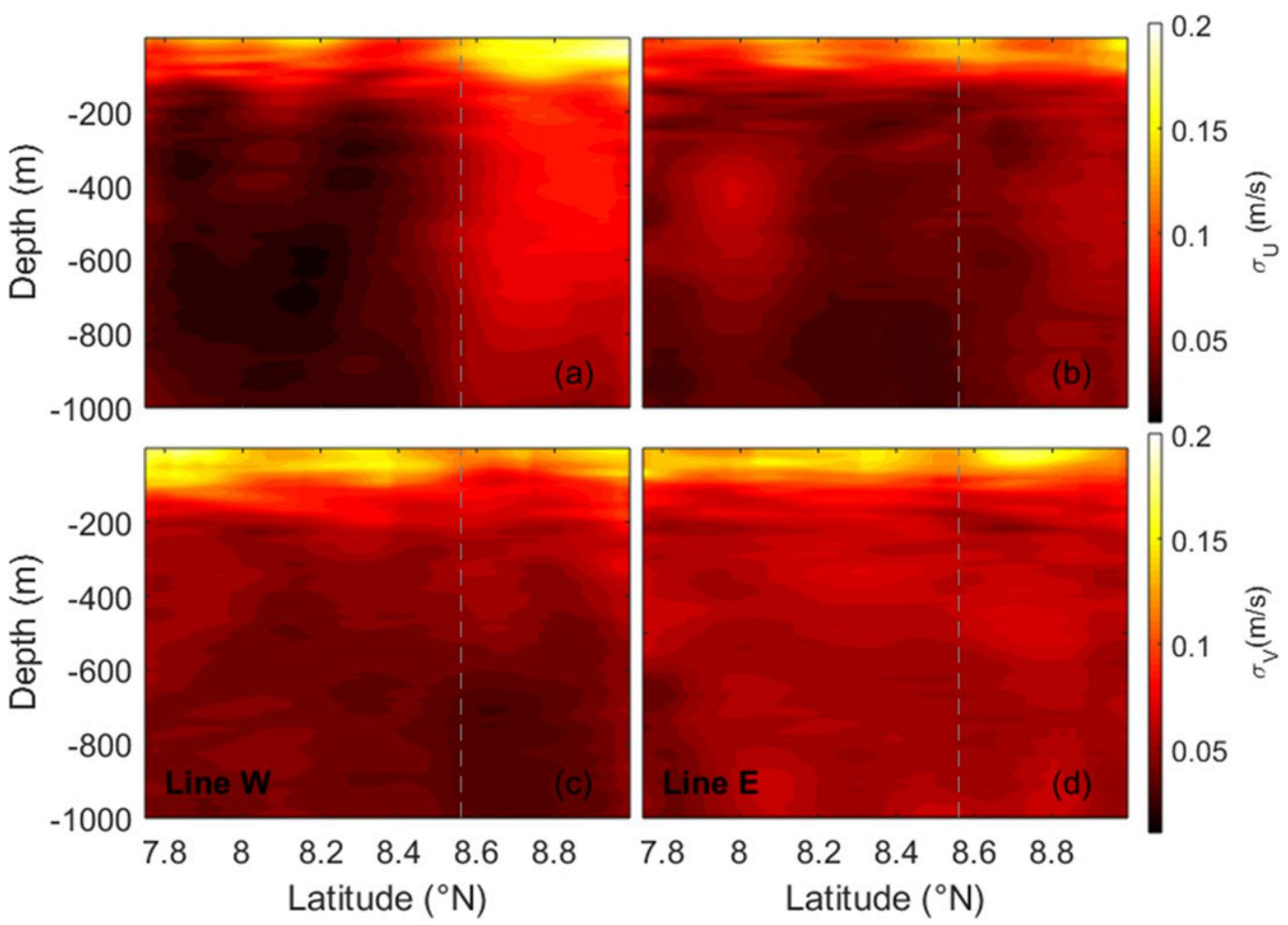

FIG. 11. (a),(b) Zonal and (c),(d) meridional velocity variability along (left) Line W and (right) Line E after selecting for westward flow. Line $\mathrm{E}$ is upstream during westward flow, and Line $\mathrm{W}$ is downstream. The patterns in variability are similar to the total mean (Fig. 8); however, subthermocline zonal velocity variability is only elevated downstream and north of the reef (gray dashed line).

in the intensified surface layer as well as throughout the water column and north of the reef. While on average there is return flow everywhere directly downstream of Palau, during westward flow the length scales in the wake reflect the local topography (i.e., Velasco reef). This may be caused by strong currents through a deep and narrow channel separating the reef from the rest of the archipelago. Mean depth-average eastward flow is accompanied by persistent westward flow at the surface and strong northward currents in the lee. While westward flow produces a distinctive vorticity signature downstream with average absolute Rossby numbers at the surface exceeding 0.3 , eastward flow does not produce comparably strong vorticity. Hovmöller diagrams of zonal velocity and normalized vorticity reveal significant variability of the wake on time scales greater than a month, and especially energetic events that induce vorticity that can exceed the local Coriolis frequency (i.e., Ro $>1$ ).

\section{a. Rossby number}

The high Ro observed in the wake of Palau has important implications. Large islands $[O(100) \mathrm{km}]$ often induce wakes with low Ro because of the inverse dependence on length. These wakes, with Ro $=O\left(10^{-1}\right)$ or smaller, are often in geostrophic balance (Caldeira and Sangra 2012; Dong et al. 2007; Aristegui et al. 1994), and can remain coherent for hundreds of kilometers downstream (Caldeira et al. 2014). For smaller islands with much higher absolute Ro $[\rightarrow O(1)]$ ageostrophic effects become important. Numerical studies have shown that wake eddies with large Ro are susceptible to destabilizing instabilities and can quickly lose their integrity downstream (a detailed treatment of these instabilities can be found in Dong et al. 2007). Caldeira and Sangra (2012) demonstrated a case where changes in the incident flow direction reduced the cross section of an oblong island, which then went from producing robust, large, geostrophic eddies to smaller, ageostrophic eddies that dissipated within a few island lengths downstream. It might be reasonable to hypothesize that Palau would have a small Ro, and subsequently produce large, geostrophic eddies. The large-scale cross section as seen by east-west flows is $\sim 200 \mathrm{~km}$, mean surface velocities of the NEC are $\sim 0.2 \mathrm{~m} \mathrm{~s}^{-1}$ (Schonau and Rudnick 2015), and the local Coriolis parameter is $\sim 2 \times 10^{-5} \mathrm{~s}^{-1}$, giving Ro $=O\left(10^{-2}\right)$. However, we have observed a mean Ro that is an order of magnitude higher $\left[O\left(10^{-1}\right)\right]$, as well as 


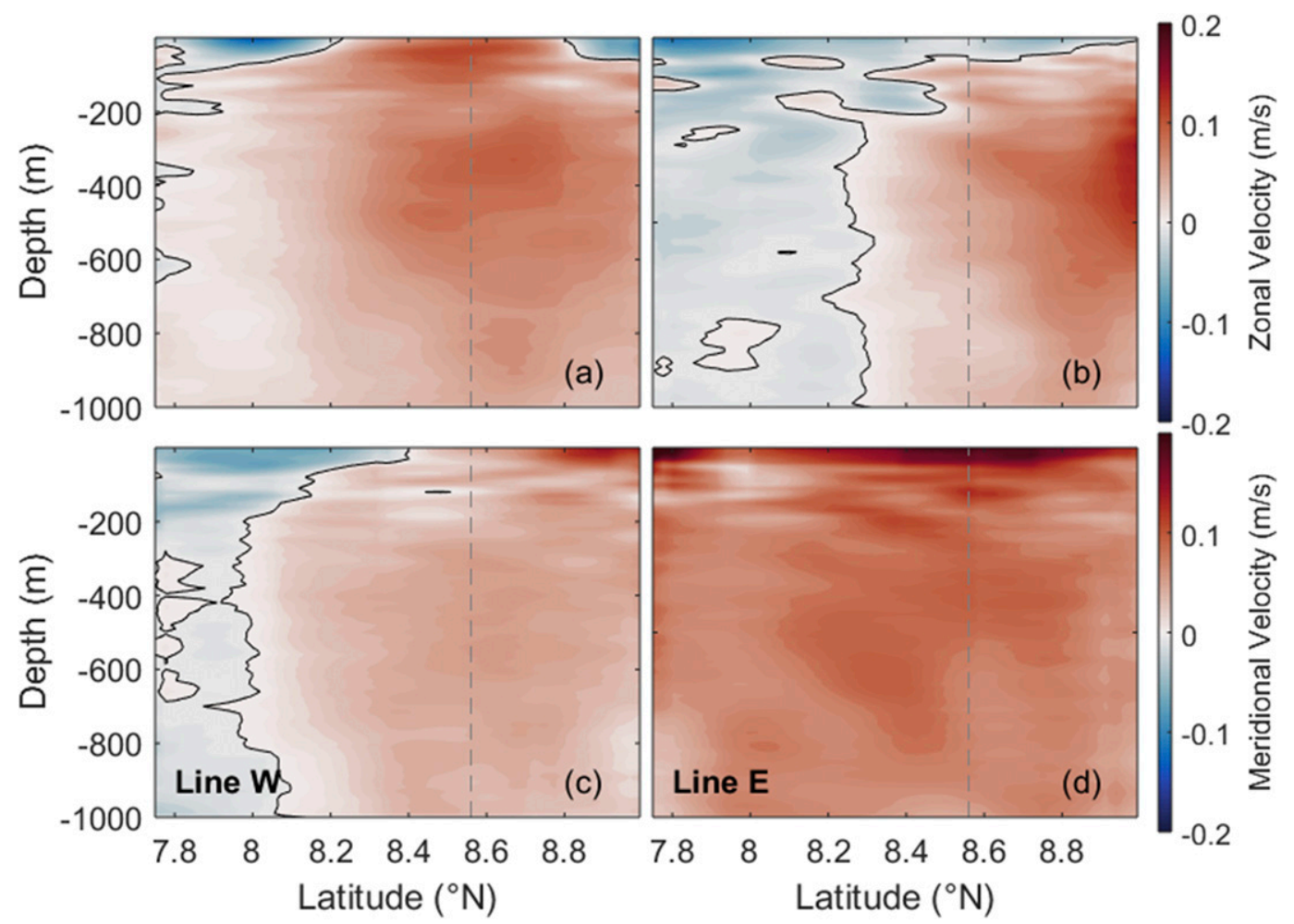

FIG. 12. Mean sections of (a),(b) zonal and (c),(d) meridional velocity along (right) Line E and (left) Line W after selecting for eastward flow. Line W is upstream during westward flow, and Line $\mathrm{E}$ is downstream. The color scheme and contour lines are as in Fig. 7. Both the incident flow and wake are asymmetric to westward flow. Despite selecting for depth-averaged eastward flow, westward currents persist at the surface in (a) and (b). While zonal velocity downstream in (b) seems to suggest return flow, the strong northward component of velocity in (d) suggests that the flow along Line E may originate from the south instead of the west.

instantaneous values that can exceed 1 . This suggests that it is unlikely these eddies are in geostrophic balance and therefore may lose their integrity within a few island lengths. If so, the wake produced by Palau may have an exclusively local impact. This interpretation is supported by the mean OSCAR surface currents around Palau, which show that the wake extends no more than $100 \mathrm{~km}$ on average to the west (Fig. 1).

\section{b. Shedding frequency}

It is useful to estimate how often wake eddies are shed from Palau. In laboratory flows, the Reynolds number $\mathrm{Re}$ controls the frequency of eddy shedding through an empirical relationship with the Strouhal number St (Zdravkovich 2000). Here $\mathrm{Re}=U L / \nu$ and $\mathrm{St}=U /\left(\omega_{e} L\right)$, where $U$ and $L$ are characteristic velocity and length scales, $\nu$ is the molecular viscosity, and $\omega_{e}$ is the shedding frequency. It is common practice to replace the molecular viscosity with a turbulent eddy viscosity $\nu_{e}$ in the ocean. This parameterization, which introduces an effective Reynolds number $\mathrm{Re}_{e}$, is supported by observations showing that the large-scale structure of island wakes with Re of up to $O\left(10^{10}\right)$ is often qualitatively similar to laminar wakes with $\operatorname{Re}$ of $O\left(10-10^{2}\right)$ (Barkley 1972). A common choice of $\nu_{e}$ is $O\left(10^{2}\right) \mathrm{m}^{2} \mathrm{~s}^{-1}$, which agrees reasonably well with direct measurements in the open ocean (Ledwell et al. 1998; Heywood et al. 1990; Chang et al. 2013; Caldeira et al. 2005; Hernández-León 1991). Here we assume $\nu_{e}=100$, keeping in mind that our estimate of the $\mathrm{Re}_{e}$ is dependent on this choice. The eddy viscosity is explored further in section $4 \mathrm{~d}$. We take $U$ to be the incident shallow current far north of topographic blocking during westward flow, $\sim 0.2 \mathrm{~m} \mathrm{~s}^{-1}$ (Fig. 9). While $L$ is typically defined as the island cross section, our observations suggest this is not the relevant scale here. We instead take $L$ to be the along-stream extent of the boundary layer, because this is the source of wake vorticity. Assuming the boundary layer develops near the blocking latitude, $L \sim 70 \mathrm{~km}$ (Fig. 9). This gives an $\operatorname{Re}_{e} \sim 140$ for the shallow surface layer during westward flow. For $40<\operatorname{Re}<400$, St is given by $0.212(1-21.2 / \mathrm{Re})($ Roshko 1954). This gives $\mathrm{St}=$ 0.18 for our estimate of $\mathrm{Re}_{e}$, which corresponds to an 


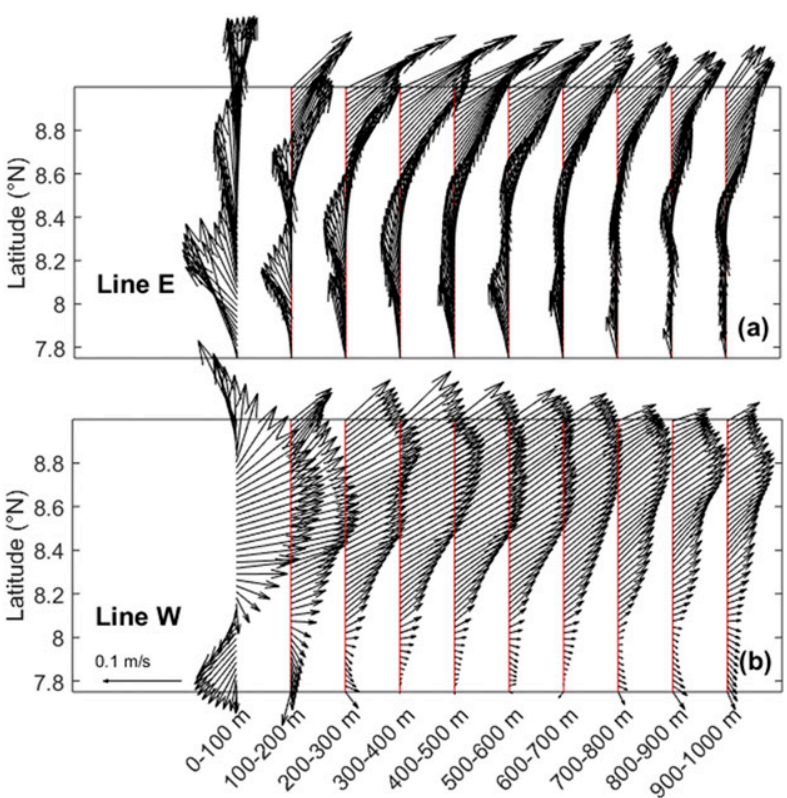

FIG. 13. Time-mean depth-average velocity vectors in intervals of $100 \mathrm{~m}$ along (a) Line E and (b) Line W, after selecting for eastward flow. Line $\mathrm{W}$ is upstream during westward flow, and Line $\mathrm{E}$ is downstream. The surface $200 \mathrm{~m}$ emphasize the convergence of flow from the southeast along Line $\mathrm{E}$ and from the west along Line $\mathrm{W}$, resulting in the persistent signature of westward flow in the mean.

eddy-shedding period of about 23 days. We have observed at least two periods of westward flow sustained for more than a month (from November 2017 through February 2016, and June through October 2017), which would suggest that eddies are shed at least a few times a year. However, velocity and vorticity variability are high, and we may expect a wide range of behavior. When the flow is weakest and $\mathrm{Re}_{e}<1$, it is likely there is no wake (Roshko 1954). At its strongest, the incident velocity can exceed $0.5 \mathrm{~m} \mathrm{~s}^{-1}$ in the shallow surface layer (Figs. 16, 17), with correspondingly high Rossby numbers $(\mathrm{Ro} \rightarrow 1)$. For these swift flows, $\mathrm{Re}_{e}$ can exceed 300. This corresponds to an eddy-shedding period of about 10 days. In other words, while the mean $\mathrm{Re}_{e}$ of Palau suggests that eddies are shed roughly monthly, in light of the observed variability it is more likely that the flow around the island oscillates between a mode of vigorous eddy shedding for sustained periods of swift westward flow, and no developed wake for periods of weak flow.

\section{c. Depth dependence}

A similar calculation of $\operatorname{Re}_{e}$ below the surface layer suggests that the dynamics in the subthermocline are possibly quite different. The $\operatorname{Re}_{e} \sim 28$, which is below the cutoff value for vortex shedding $\left(U \sim 0.07 \mathrm{~m} \mathrm{~s}^{-1}\right.$ and
$L \sim 40 \mathrm{~km}$ ). While eddies may be shed in the shallow surface layer on average, it is possible that they remain attached to the island in the subthermocline. One way to evaluate the dynamic link between the surface and subthermocline current is to look at their relative transport variability. Schonau and Rudnick (2015) found the section integrated zonal transport across the NEC in the surface layer to be strongly correlated with transport in the NEUCs. They report a transport correlation value of $R=0.87$. In this study there is a similarly high correlation between the surface and subthermocline flow along Line $\mathrm{E}$ (upstream in the mean), $R=0.71$ across the total time series. However, along Line $\mathrm{W}$ (downstream in the mean) it drops to $R=0.45$. This is consistent with the inference that the surface and the subsurface flow become decoupled due to their different dynamic responses to the island. It is worth noting that when considering the depth structure of the wake we must acknowledge an additional length scale, the deformation radius $\mathrm{Rd}$. An estimate of $\mathrm{Rd}$ using mean shear and stratification near Palau gives $\mathrm{Rd}=$ $O(100 \mathrm{~km})$, on par with the island length scale. This suggests that the effects of stratification in determining the wake dynamics are nonnegligible, further complicating the relationship between the surface and subthermocline wake.

\section{d. Eddy viscosity}

There are physical reasons that $\nu_{e}=O(100)$ may be an appropriate estimate of the turbulent eddy viscosity around Palau. In a numerical study of idealized turbulent island wakes, Dong et al. (2007) found that the boundary layer obeyed a similar power law to that of a viscous boundary layer $\left(\delta \sim \operatorname{Re}^{1 / 4}\right.$, where $\delta$ is the width of the boundary layer; Walker and Stewartson 1972). Motivated by this and the broad similarities between island wakes and laminar flows, we will apply laminar boundary layer theory to estimate the eddy viscosity. The width of a laminar boundary layer is given by $\delta(L)=5(\nu L / U)^{1 / 2}$ (Blasius 1908), and the vorticity across the boundary layer at separation is given by $\zeta=$ $U / \delta(L)$. The eddy viscosity can thus be written in terms of the velocity, vorticity, and length scales as $\nu_{e} \sim \delta^{2} U /(25 L) \rightarrow U^{3} /\left(25 L \zeta^{2}\right)$. We can estimate the scale of the boundary layer vorticity from the values observed downstream near the surface during westward flow $\left(\zeta \sim 7 \times 10^{-6} \mathrm{~s}^{-1} ;\right.$ Fig. 14). With our length and velocity scales defined above, this gives $\nu_{e} \sim$ $90 \mathrm{~m}^{2} \mathrm{~s}^{-1}$, in good agreement with values typically assumed in other island wake studies. There is further evidence to suggest that this value is physically meaningful. As part of another study in the FLEAT program, a ship survey was conducted around Velasco 


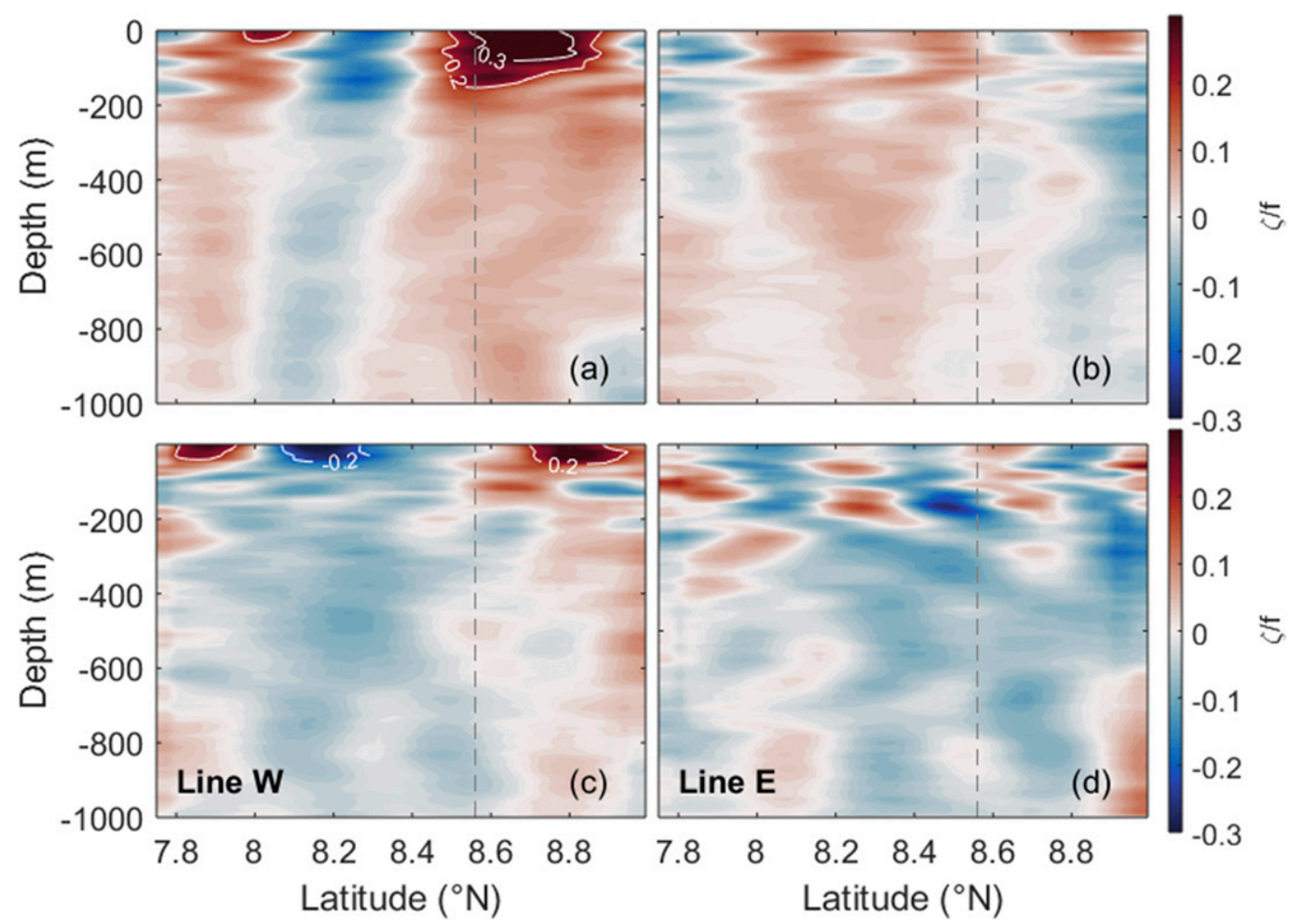

FIG. 14. Mean sections of normalized vorticity (Ro) calculated from the meridional gradient of zonal velocity $(\zeta=d U / d y)$, during (a),(b) westward flow and (c),(d) eastward flow along (left) Line W and (right) Line E. The $\mid$ Ro $\mid$ greater than 0.2 have been contoured in white, with an interval of 0.1 . The gray dashed line is the maximum latitude of Velasco reef. During westward flow, Line E is upstream and Line W is downstream. During eastward flow this is reversed. The Ro upstream during westward flow in (b) is on average less than \pm 0.1 . Downstream of the reef, Ro increases substantially to over 0.3 on the surface in (a), suggesting that there are times when ageostrophic effects are important. During westward flow, vorticity has latitudinal structure throughout the water column. During eastward flow, Ro in the wake is low $(<0.1$ on average $)$ and there is no symmetric vorticity signature, except on the surface in (c) where westward flow persists.

in June 2016. Strong tidal currents $\left[O\left(10^{-1}\right) \mathrm{m} \mathrm{s}^{-1}\right]$ were observed to generate eddies about $1 \mathrm{~km}$ in scale. If these types of eddies are the dominant process responsible for transferring momentum within the mesoscale boundary layer, we can estimate an associated eddy viscosity as the product of their speed and pathlength, that is, $\nu_{e} \sim 100 \mathrm{~m}^{2} \mathrm{~s}^{-1}$ (Vallis 2006). This value is consistent with both our boundary layer estimate and the literature. These arguments are speculative, but their agreement with the literature supports our choice of eddy viscosity and the subsequent inferences about wake behavior.

\section{e. Regional context}

Mean velocity and vorticity sections are fundamentally different during eastward and westward flow (Figs. 9, 12, 14). OSCAR surface currents and normalized surface vorticity (Ro) averaged over westward and eastward flow reveal that the regional context for the two flow regimes differs substantially
(Fig. 18). On average during westward flow a strong southeastward NECC passes closely to the southern tip of Palau and a steady broad westward NEC extends from the north to just south of the island. There is a strong negative vorticity signature directly to the west of the southern end of Palau, and a weaker positive one west of the northern end. This is the wake induced by flow around Palau. During eastward flow, the NECC moves southward and increases in intensity. This shift is accompanied by the development of a strong northwestward current directly south of Palau that further intensifies the negative vorticity signature in the lee of the island. This feature dominates the wake, and the northern end of Palau is consumed by return flow from the south. However, the NEC persists and the surface currents converge around Velasco, as evident in surface depth-average velocity (Fig. 13). This shift in the regional circulation is consistent with the seasonal variability in the region identified by Hsin and Qiu (2012). Using OSCAR 


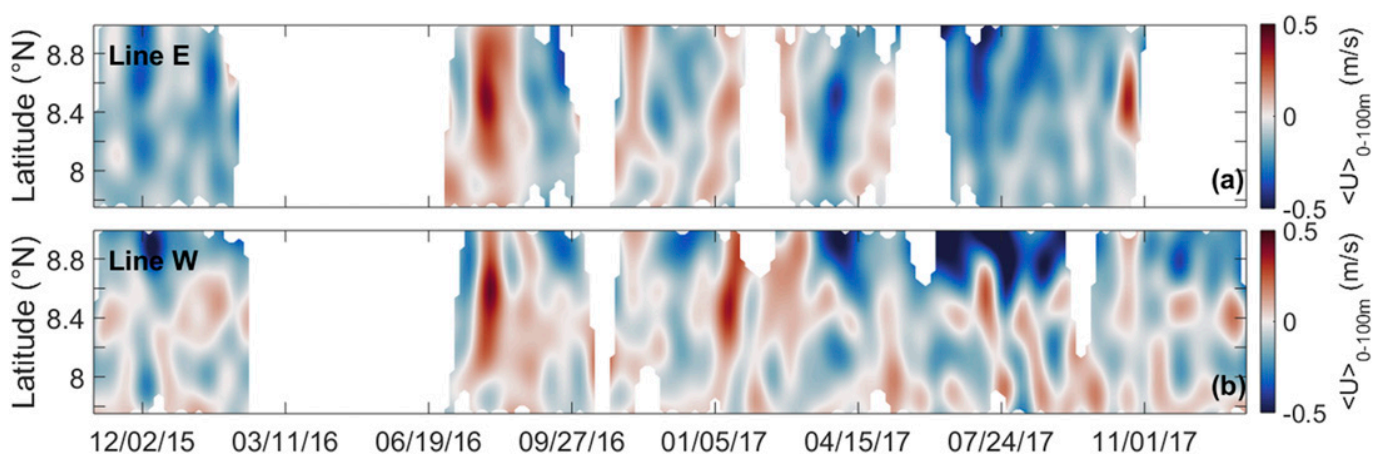

FIG. 15. Hovmöller diagrams of shallow (0-100 m) zonal velocity along (a) Line E and (b) Line W. Return flow in the lee of the reef appears as an intermittent band of eastward velocity around $8.4^{\circ} \mathrm{N}$ along Line $\mathrm{W}$. There are highfrequency (i.e., days) fluctuations in the current of moderate magnitude, but the time series is dominated by lowfrequency (i.e., weeks-months), highly energetic events.

surface currents averaged over an 18-yr period they show that the NECC west of $140^{\circ} \mathrm{E}$ moves southward in the winter/spring and northward in the summer/autumn, driven by the westward propagation of downwelling Rossby waves. Out of three major eastward events observed, two occur in the winter (2016 and 2017, not shown) consistent with this seasonal migration. They are characterized by persistent westward flow at the surface and eastward flow in the subthermocline. The third event occurred in July 2016 and was characterized by a weak NECC and increased eddy activity throughout the entire region. It was also the only period in the glider time series with strong eastward flow at the surface. This disruption of the regional circulation was likely caused by relaxation of the 2015-16 El Niño event (Lim et al. 2017). One of the motivations for this paper was examining potential asymmetries between wakes generated by otherwise symmetric eastward and westward flow, as predicted by quasigeostrophic theory (Boyer and Davies 1982; Musgrave et al. 2018). However, the seasonal and interannual variability of the regional circulation detailed here indicates that eastward flow is not a simple current reversal of the NEC. Instead it is the result of complicated interactions between the NEC, NECC, and Palau, obscuring such inferences.

\section{Conclusions}

In this paper we have presented sustained (2 years) observations of a large island wake using autonomous underwater gliders. On average flow impinges on the island from the east, accelerates around the topography and separates, leading to return flow in the lee of the island. We have demonstrated that this return flow is confined to a region that is much smaller than the total cross section of the island because of details of the topography, and we have linked this reduced length scale to high Rossby numbers in the wake.

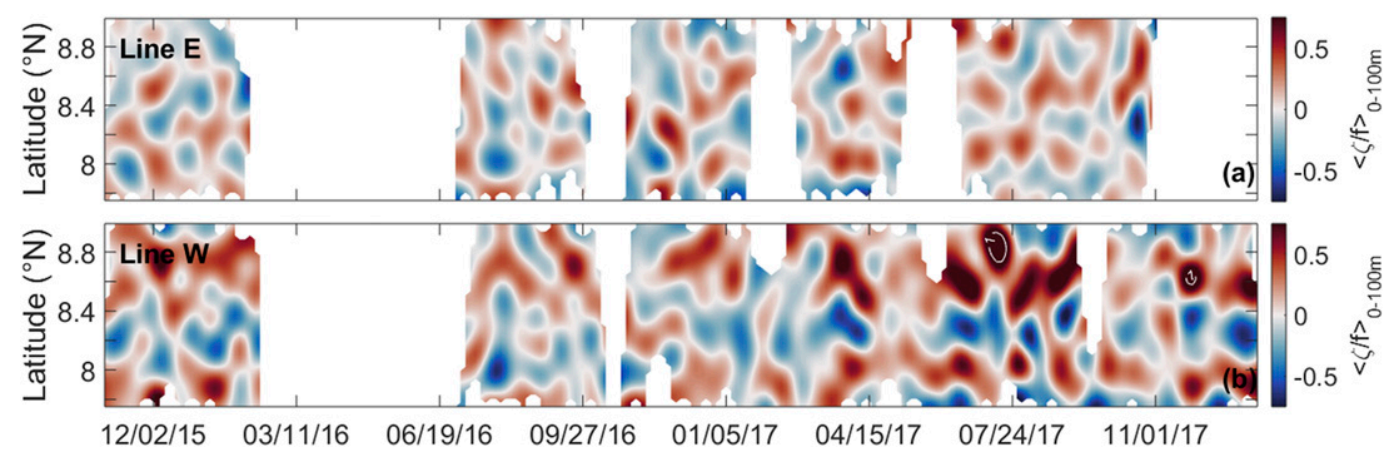

FIG. 16. Hovmöller diagrams of shallow $(0-100 \mathrm{~m})$ normalized vorticity (Rossby number) along (a) Line E and (b) Line W. The low-frequency, energetic events in zonal velocity (Fig. 15) have important implications for the vorticity. For example, anomalously strong westward flow in July 2017 corresponds to Ro exceeding 1 in the surface wake [white contour in (b)]. 

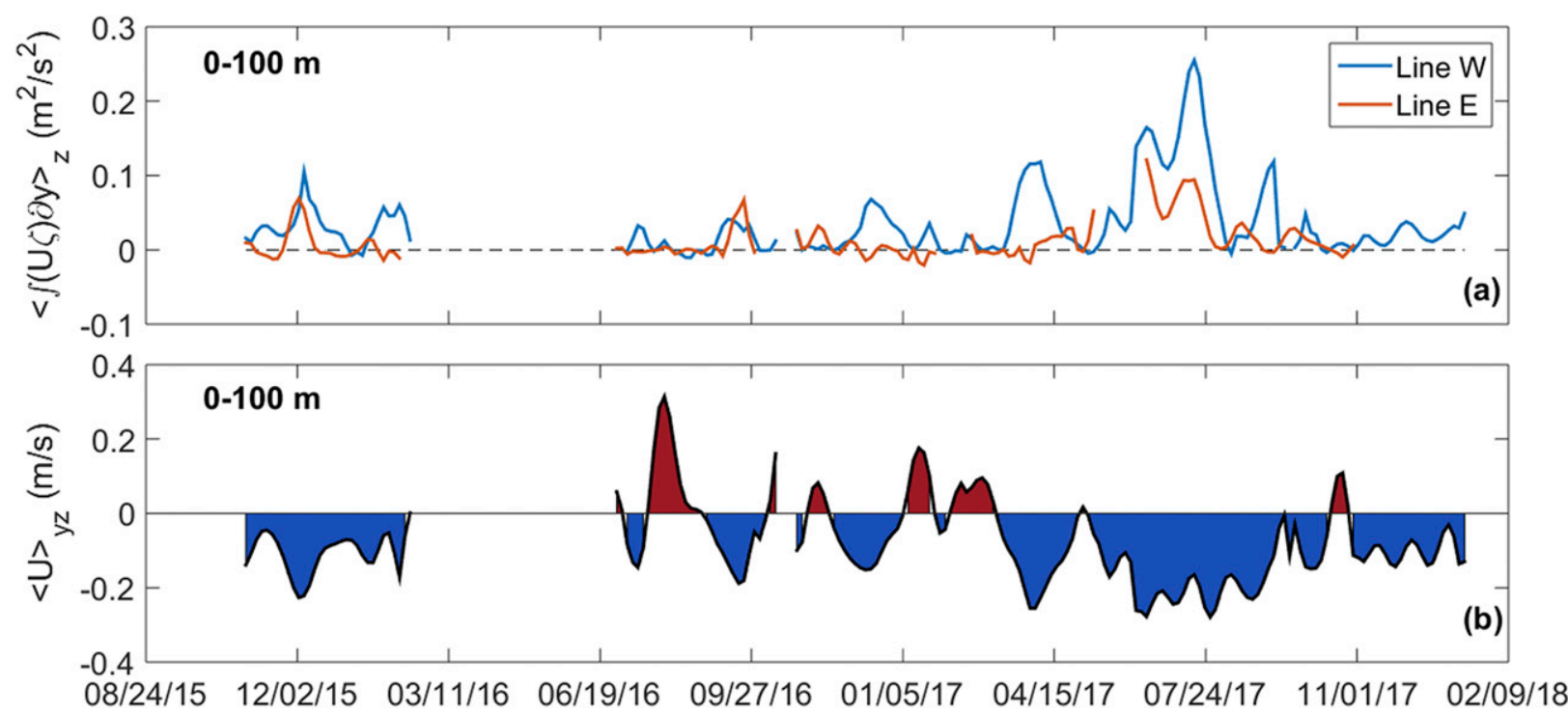

FIG. 17. (a) Depth-average, section-integrated vorticity flux $\zeta U$ along both lines, as well as (b) depth- and latitude-average zonal velocity north of $8.2^{\circ} \mathrm{N}$ along Line E. Periods of sustained westward flow correspond to elevated vorticity flux downstream, emphasizing the role the island plays in vorticity production. However, periods of weak and intermittent westward flow fail to contribute substantially to the vorticity production.

As with most island wake studies, the incident flow and wake around Palau were shown to be highly variable. This is in part due to energetic low-frequency, large-scale events in which the flow direction often reverses. We have shown that the extremes (energetic eastward and westward flow) exist under different regional current conditions. It is suggested here that for the weakest incident currents there may be no flow separation, whereas the swiftest flows develop eddies with high Ro that shed on the order of days. Further, we have suggested that the dynamic link between the surface currents (the NEC) and the undercurrents (the NEUCs) found by Schonau and Rudnick (2015) is likely decoupled as a result of the interaction with the island. This may be due to shear of the incident current and the subsequent order of magnitude difference in the Rossby number of the surface and subthermocline wakes we have observed.

Knowledge of such nondimensional parameters enables comparisons between islands across a wide range of scales, as well as with idealized numerical studies and theory. However they are often inferred indirectly from sparse observations. The timedependent Ro measured in this study is up to an order of magnitude larger than what might be inferred from a reasonable back of the envelope estimate based on knowledge of the velocity alone. This suggests that ageostrophic effects may often be important to first order in the wake of Palau, and subsequent destabilizing instabilities may limit its zonal extent.
This finding underscores the need for sustained island wake observations, as limited synoptic surveys may not capture such strong vorticity.

In sum, a primary conclusion of this study is that the variability of the flow around Palau leads to a wide range of dynamics in its wake. Estimates of the vorticity generated by islands which fail to account for this variability will likely misrepresent the net vorticity flux into the interior over time. An improved understanding of how intrinsic flow variability influences vorticity production is necessary to continue building on the significant insights provided by idealized studies (e.g., Dong and McWilliams 2007; Heywood et al. 1996; Jimenez et al. 2008). For example, as is common practice with geophysical flows we have used an assumed eddy viscosity to determine the Reynolds number. We have hypothesized that the value obtained may be physically meaningful by linking it to the size and velocity of small-scale, highfrequency tidal eddies observed around Velasco. Further work is required to test the validity of this speculation, and explore the relationship between small-scale processes near topography and large-scale wakes. While the parameterization of momentum diffusivity using an eddy viscosity is founded on physical principles that are well understood, the dependence of this value on the larger scale flow has not been explored in great detail. This is in no small part due to the difficulty in observing a wide range of scales at once. A more complete understanding of the wake produced around Palau will hinge on 


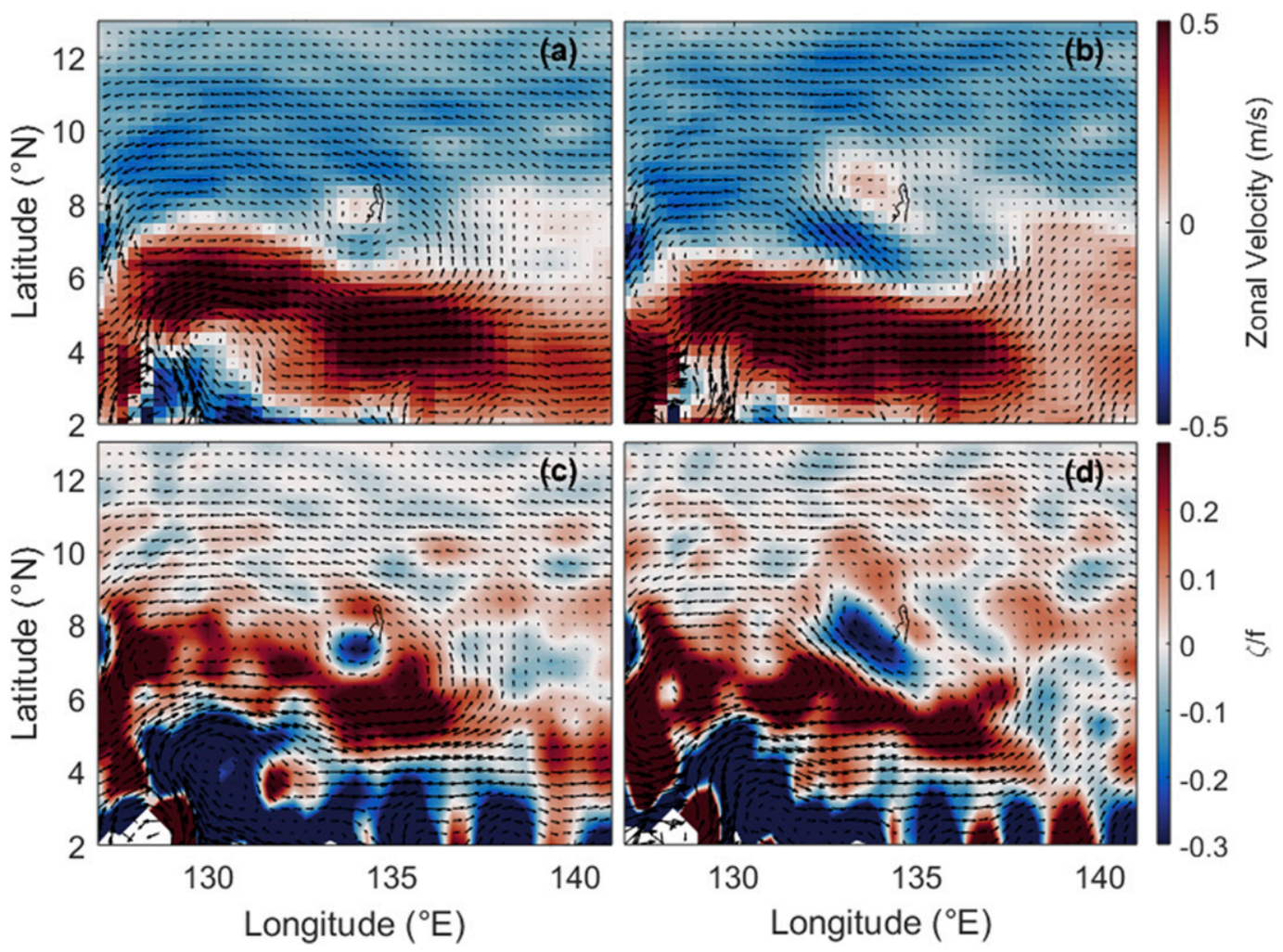

FIG. 18. OSCAR surface currents averaged over the observational periods corresponding to (a),(c) westward and (b),(d) eastward flow provide regional context for the asymmetries observed by the glider during flow reversals. Black arrows are surface current vectors, plotted over filled contours of (top) zonal velocity and normalized vorticity, or (bottom) Rossby number. Depth-average westward (eastward) flow as seen by the glider is characterized by a more northward (southward) NECC in the vicinity of Palau. These regional differences impact the local flow around Velasco, likely contributing to the observed asymmetries.

elucidating the vorticity generated across a wide range of scales. This is the subject of future FLEAT studies.

Acknowledgments. Spray underwater glider data used in this paper are available online (https://spraydata.ucsd.edu). OSCAR surface currents referenced in this paper were obtained from the JPL Physical Oceanography DAAC and were developed by ESR (ESR 2009). Glider observations and analysis were funded by the Office of Naval Research as part of the Flow Encountering Abrupt Topography (FLEAT) project through Grant N00014-15-1-2488. We thank the Instrument Development Group at Scripps Institution of Oceanography for all facets of the operations of Spray underwater gliders. We thank Pat and Lori Colin at the Coral Reef Research Foundation for their support in Palau.

\section{REFERENCES}

Andrade, I., P. Sangra, S. Hormazabal, and M. Correa-Ramirez, 2014: Island mass effect in the Juan Fernández Archipelago
(33으), Southeastern Pacific. Deep-Sea Res. I, 84, 86-99, https://doi.org/10.1016/j.dsr.2013.10.009.

Aristegui, J., and M. F. Montero, 2005: Temporal and spatial changes in plankton respiration and biomass in the Canary Islands region: the effect of mesoscale variability. J. Mar. Syst., 54, 65-82, https://doi.org/10.1016/j.jmarsys.2004.07.004.

, P. Sangra, S. Hernández-León, M. Canton, A. HernandezGuerra, and J. L. Kerling, 1994: Island induced eddies in the Canary Islands. Deep-Sea Res., 41, 1509-1525, https://doi.org/ 10.1016/0967-0637(94)90058-2.

Barkley, R. A., 1972: Johnston Atoll's wake. J. Mar. Res., 30, 201-216. Blasius, H., 1908: The boundary layers in fluids with little friction. Z. Math. Phys., 56, 1-37.

Bonjean, F., and G. Lagerloef, 2002: Diagnostic model and analysis of the surface currents in the tropical Pacific ocean. J. Phys. Oceanogr., 32, 2938-2954, https://doi.org/10.1175/1520-0485(2002) 032<2938:DMAAOT $>2.0$.CO;2.

Bowman, M. J., D. E. Dietrich, and C. A. Lin, 1996: Observations and modeling of mesoscale ocean circulation near a small island. Small Islands Marine Science and Sustainable Development, G. A. Maul, Ed., Coastal and Estuarine Studies, Vol. 51, Amer. Geophys. Union, 18-35, https://doi.org/10.1029/ CE051p0018.

Boyer, D. L., and P. A. Davies, 1982: Flow past a circular cylinder on a $\beta$-plane. Philos. Trans. Roy. Soc. London, 306A, 533-556, https://doi.org/10.1098/rsta.1982.0094. 
Caldeira, R. M. A., and P. Sangra, 2012: Complex geophysical wake flows: Madeira Archipelago case study. Ocean Dyn., 62, 683700, https://doi.org/10.1007/s10236-012-0528-6.

_ , P. Marchesiello, N. P. Nezlin, P. M. DiGiacomo, and J. C. McWilliams, 2005: Island wakes in the Southern California Bight. J. Geophys. Res., 110, C11012, https://doi.org/10.1029/ 2004JC002675.

, A. Stenger, X. Couvelard, I. B. Araujo, P. Testor, and A. Lorenzo, 2014: Evolution of an oceanic anticyclone in the lee of Madeira Island: In situ and remote sensing survey. J. Geophys. Res. Oceans, 119, 1195-1216, https://doi.org/ 10.1002/2013JC009493.

Chang, M. H., T. Y. Tang, C. R. Ho, and S. Y. Chao, 2013: Kuroshio-induced wake in the lee of Green Island off Taiwan. J. Geophys. Res. Oceans, 118, 1508-1519, https://doi.org/ 10.1002/jgrc.20151.

Chelton, D., R. Deszoeke, M. Schax, K. E. Naggar, and N. Siwertz, 1998: Geographical variability of the first baroclinic Rossby radius of deformation. J. Phys. Oceanogr., 28, 433-460, https://doi.org/ 10.1175/1520-0485(1998)028<0433:GVOTFB > 2.0.CO;2.

Dickey, T. D., F. Nencioli, V. S. Kuwahara, C. Leonard, W. Black, Y. M. Rii, R. R. Bidigare, and Q. Zhang, 2008: Physical and bio-optical observations of oceanic cyclones west of the island of Hawai'i. Deep-Sea Res. II, 55, 1195-1217, https://doi.org/ 10.1016/j.dsr2.2008.01.006.

Dong, C., and J. C. McWilliams, 2007: A numerical study of island wakes in the Southern California Bight. Cont. Shelf Res., 27, 1233-1248, https://doi.org/10.1016/j.csr.2007.01.016.

$\longrightarrow, \ldots$, and A. F. Shchepetkin, 2007: Island wakes in deep water. J. Phys. Oceanogr., 37, 962-981, https://doi.org/10.1175/ JPO3047.1.

ESR, 2009: OSCAR third degree resolution ocean surface currents, version 1. PO.DAAC, accessed 22 August 2018, https:// doi.org/10.5067/OSCAR-03D01.

Hernández-León, S., 1991: Accumulation of mesozooplankton in a wake area as a causative mechanism of the "island-mass effect." Mar. Biol., 109, 141-147, https://doi.org/10.1007/BF01320241.

Heron, S. F., E. J. Metzger, and W. J. Skirving, 2006: Seasonal variations of the ocean surface circulation in the vicinity of Palau. J. Oceanogr., 62, 413-426, https://doi.org/10.1007/ s10872-006-0065-3.

Heywood, K. J., E. D. Barton, and J. H. Simpson, 1990: The effects of flow disturbance by an oceanic island. J. Mar. Res., 48, 55-73, https://doi.org/10.1357/002224090784984623.

_ D. P. Stevens, and G. R. Bigg, 1996: Eddy formation behind the tropical island of Aldabra. Deep-Sea Res. I, 43, 555-578, https://doi.org/10.1016/0967-0637(96)00097-0.

Hsin, Y. C., and B. Qiu, 2012: Seasonal fluctuations of the surface North Equatorial Countercurrent (NECC) across the Pacific Basin. J. Geophys. Res., 117, C06001, https://doi.org/10.1029/ 2011JC007794.

Hsu, P. C., M. H. Chang, C. C. Lin, S. J. Huang, and C. R. Ho, 2017: Investigation of the island-induced ocean vortex train of the Kuroshio Current using satellite imagery. Remote Sens. Environ., 193, 54-64, https://doi.org/10.1016/j.rse.2017.02.025.

Jimenez, B., P. Sangra, and E. Mason, 2008: A numerical study of the relative importance of wind and topographic forcing on oceanic eddy shedding by tall, deep water islands. Ocean Modell., 22, 146-157, https://doi.org/10.1016/j.ocemod.2008.02.004.

Kashino, Y., N. Espana, F. Syamsudin, K. Richards, T. Jensen, P. Dutrieux, and A. Ishida, 2009: Observations of the North Equatorial Current, Mindanao Current, and Kuroshio Current system during the 2006/07 El Nino and 2007/08 La Nina.
J. Oceanogr., 65, 325-333, https://doi.org/10.1007/s10872-0090030-z.

Kundu, P. K., and I. M. Cohen, 1990: Fluid Mechanics. 4th ed. Elsevier, 904 pp.

Ledwell, J. R., A. J. Watson, and C. S. Law, 1998: Mixing of a tracer in the pycnocline. J. Geophys. Res., 103, 21 499-21 529, https:// doi.org/10.1029/98JC01738.

Lim, Y. K., R. M. Kovach, S. Pawson, and G. Vernieres, 2017: The 2015/16 El Nino event in context of the MERRA-2 reanalysis: A comparison of the Tropical Pacific with 1982/83 and 1997/ 98. J. Climate, 30, 4819-4842, https://doi.org/10.1175/JCLI-D16-0800.1.

Musgrave, R. C., G. Flierl, and T. Peacock, 2018: The generation of Rossby waves and wake eddies by small islands. J. Mar. Res., 76, 63-91, https://doi.org/10.1357/002224018824845929.

Qiu, B., and R. Lukas, 1996: Seasonal and interannual variability of the North Equatorial Current, the Mindanao Current, and the Kuroshio along the Pacific western boundary. J. Geophys. Res., 101, 12 315-12 330, https://doi.org/10.1029/95JC03204.

_ S. Chen, and H. Sasaki, 2013a: Generation of the North Equatorial Undercurrent jets by triad baroclinic Rossby wave interactions. J. Phys. Oceanogr., 43, 2682-2698, https://doi.org/ 10.1175/JPO-D-13-099.1.

—, D. L. Rudnick, S. Chen, and Y. Kashino, 2013b: Quasistationary North Equatorial Undercurrent jets across the tropical North Pacific Ocean. Geophys. Res. Lett., 40, 21832187, https://doi.org/10.1002/grl.50394.

Roshko, A., 1954: On the development of turbulent wakes from vortex streets. National Advisory Committee for Aeronautics Rep. 1191, 25 pp.

Rudnick, D. L., 2001: On the skewness of vorticity in the upper ocean. Geophys. Res. Lett., 28, 2045-2048, https://doi.org/ 10.1029/2000GL012265.

— water gliders. J. Geophys. Res., 116, C08010, https://doi.org/ 10.1029/2010JC006849.

— J. T. Sherman, and A. P. Wu, 2018: Depth-average velocity from Spray underwater gliders. J. Atmos. Oceanic Technol., 35, 1665-1673, https://doi.org/10.1175/JTECH-D-17-0200.1.

Sangra, P., and Coauthors, 2007: On the nature of oceanic eddies shed by the Island of Gran Canaria. Deep-Sea Res. I, 54, 687709, https://doi.org/10.1016/j.dsr.2007.02.004.

Schonau, M. C., and D. L. Rudnick, 2015: Glider observations of the North Equatorial Current in the western tropical Pacific. J. Geophys. Res. Oceans, 120, 3586-3605, https://doi.org/ 10.1002/2014JC010595.

Shcherbina, A. Y., E. A. D'Asaro, C. M. Lee, J. M. Klymak, M. J. Molemaker, and J. C. McWilliams, 2013: Statistics of vertical vorticity, divergence, and strain in a developed submesoscale turbulence field. Geophys. Res. Lett., 40, 4706-4711, https:// doi.org/10.1002/grl.50919.

Sherman, J., R. E. Davis, W. B. Owens, and J. Valdes, 2001: The autonomous underwater glider "Spray." IEEE J. Oceanic Eng., 26, 437-446, https://doi.org/10.1109/48.972076.

Smith, W. H. F., and D. T. Sandwell, 1997: Global seafloor topography from satellite altimetry and ship depth soundings: Evidence for stochastic reheating of the oceanic lithosphere. Science, 277, 1956-1962, https://doi.org/10.1126/ science.277.5334.1956.

Teague, W. J., G. A. Jacobs, H. T. Perkins, and J. W. Book, 2002: Low-frequency current observations in the Korea/Tsushima Strait. J. Phys. Oceanogr., 32, 1621-1641, https://doi.org/ 10.1175/1520-0485(2002)032<1621:LFCOIT > 2.0.CO;2. 
, P. A. Hwang, G. A. Jacobs, J. W. Book, and H. T. Perkins, 2005: Transport variability across the Korea/Tsushima Strait and the Tsushima Island wake. Deep-Sea Res. II, 52, 1784 1801, https://doi.org/10.1016/j.dsr2.2003.07.021.

Teinturier, S., A. Stegner, H. Didelle, and S. Viboud, 2010: Smallscale instabilities of an island wake flow in a rotating shallowwater layer. Dyn. Atmos. Oceans, 49, 1-24, https://doi.org/ 10.1016/j.dynatmoce.2008.10.006.

Todd, R. E., D. L. Rudnick, J. T. Sherman, W. B. Owens, and L. George, 2017: Absolute velocity estimates from autonomous underwater gliders equipped with Doppler current profilers. J. Atmos. Oceanic Technol., 34, 309-333, https:// doi.org/10.1175/JTECH-D-16-0156.1.
Vallis, G., 2006: Atmospheric and Oceanic Fluid Dynamics. Cambridge University Press, $745 \mathrm{pp}$.

Walker, J. D. A., and K. Stewartson, 1972: The flow past a circular cylinder in a rotating frame. Z. Angew. Math. Phys., 23, 745752, https://doi.org/10.1007/BF01602641.

Whitt, D. B., and L. N. Thomas, 2013: Near-inertial waves in strongly baroclinic currents. J. Phys. Oceanogr., 43, 706-725, https://doi.org/10.1175/JPO-D-12-0132.1.

Xie, S. P., W. T. Liu, Q. Liu, and M. Nonaka, 2001: Far-reaching effects of the Hawaiian Islands on the Pacific ocean-atmosphere system. Science, 292, 2057-2060, https://doi.org/10.1126/science.1059781.

Zdravkovich, M., 2000: Flow around Circular Cylinders. Vol. 1: Fundamentals, Oxford University Press, 694 pp. 